\title{
Onset of autumn senescence in High Arctic plants shows similar patterns in natural and experimental snow depth gradients ${ }^{1}$
}

\author{
Friederike Gehrmann, Camille Ziegler, and Elisabeth J. Cooper
}

\begin{abstract}
Predicted changes in snow cover and temperature raise uncertainties about how the beginning and the end of the growing season will shift for Arctic plants. Snowmelt timing and temperature are known to affect the timing of bud burst, but their effects on autumn senescence are less clear. To address this, researchers have examined senescence under natural and experimental environmental gradients. However, these approaches address different aspects of plant responses and the extent to which they can be compared is poorly understood. In this study, we show that the effect of snowmelt timing on the timing of autumn senescence in High Arctic plants is the same between a natural and an experimental gradient in three out of four studied species. While the two approaches mostly produce comparable results, they give in combination greater insight into the phenological responses to predicted climate changes. We also showed that a short warming treatment in autumn delayed senescence by 3.5 days in Dryas octopetala L., which is a $10 \%$ extension of the growing season end for this species. Warming treatments have commonly been applied to the whole growing season, but here we show that even isolated autumn warming can be sufficient to affect plant senescence.
\end{abstract}

Key words: senescence, phenology, natural gradient, experimental gradient, warming.

Résumé : Les changements prévus dans la couverture de neige et la température soulèvent des incertitudes quant à la façon dont le début et la fin de la saison de croissance se déplaceront pour les plantes arctiques. On sait que la date de la fonte des neiges et la température influent sur le moment du débourrement, mais leurs effets sur la sénescence automnale sont moins clairs. Pour y répondre, les chercheurs ont examiné la sénescence sous des gradients environnementaux naturels et expérimentaux. Cependant, ces approches abordent différents aspects des réponses des plantes et la mesure dans laquelle elles peuvent être comparées est mal comprise. Dans cette étude, les auteurs montrent que l'effet du moment de la fonte des neiges sur le moment de la sénescence automnale des plantes du Haut-Arctique est le même entre un gradient naturel et un gradient expérimental chez trois des quatre espèces étudiées. Bien que les deux approches produisent essentiellement des

\footnotetext{
Received 3 November 2020. Accepted 28 June 2021.

F. Gehrmann.* Organismal and Evolutionary Biology Research Programme, Viikki Plant Science Centre, University of Helsinki, Helsinki, Finland.

C. Ziegler. UMR EcoFoG Group, Institut national de la recherche agronomique, Paris, Île-de-France, France; UMR EEF Group, Institut national de la recherche agronomique, Université de Lorraine, Paris, Île-de-France, France.

E.J. Cooper. Northern Populations Research Group, Department of Arctic and Marine Biology, Faculty of Bioscience, Fisheries and Economics, UIT - The Arctic University of Norway, Tromsø, Norway.

Corresponding author: Elisabeth J. Cooper (email: elisabeth.cooper@uit.no).

${ }^{1}$ This paper is part of a Special Issue entitled: Impacts of climate change on tundra ecosystems: Three decades of results from the International Tundra Experiment (ITEX).

*Present address: Climate Impacts Research Centre, Department of Ecology and Environmental Science, Umeå University, Umeå, Sweden.

(C) 2021 The Author(s). This work is licensed under a Creative Commons Attribution 4.0 International License (CC BY 4.0) http://creativecommons.org/licenses/by/4.0/, which permits unrestricted use, distribution, and reproduction in any medium, provided the original author(s) and source are credited.
} 
résultats comparables, elles donnent en combinaison un meilleur aperçu des réponses phénologiques aux changements climatiques prévus. Ils ont également montré qu'un court traitement de réchauffement en automne retardait la sénescence de 3,5 jours chez Dryas octopetala L., ce qui représente une extension de 10 \% de la fin de la saison de croissance pour cette espèce. Les traitements de réchauffement ont généralement été appliqués à l'ensemble de la saison de croissance, mais les auteurs montrent ici que même un réchauffement isolé en automne peut être suffisant pour affecter la sénescence des plantes. [Traduit par la Rédaction]

Mots-clés : sénescence, phénologie, gradient naturel, gradient expérimental, réchauffement.

\section{Introduction}

Climate is changing most rapidly in the Arctic with mean annual temperatures rising twice as fast as the global average (IPCC 2013). However, the seasons are not affected equally and the autumn is warming disproportionally more than the summer (Chylek et al. 2009; Serreze et al. 2009). In addition, higher temperatures in late winter and spring may lead to earlier snowmelt, while the increase in snowfall predicted for some areas of the Arctic may delay snowmelt, with large regional variations (McBean et al. 2005; Räisänen 2008). This could affect the timing of bud burst and shift the end of the growing season for plants (Semenchuk et al. 2016). These changes in temperature and snow cover raise uncertainties about how the end of the growing season will shift for Arctic plants, with implications for multiple key ecosystem processes (Cooper 2014).

Due to the short growing season in the Arctic tundra, the timing of autumn senescence is important for maximising the period for plant growth and reproduction and allowing sufficient time for the development of frost hardiness and nutrient resorption. Early and sudden frost events can inhibit the development of frost hardiness, causing premature leaf fall, loss of nutrients due to incomplete resorption, and damage to shoots, with possible consequences for plant fitness (May and Killingbeck 1992). Despite its importance, autumn senescence is still far less studied than spring phenology, especially in tundra ecosystems (Gallinat et al. 2015). It is currently unclear what drives the timing of autumn senescence in Arctic plants, but indirect effects of snowmelt timing (Keenan and Richardson 2015; Semenchuk et al. 2016) and direct effects of photoperiod and temperature have been suggested (Barnes et al. 1998; Marchand et al. 2004).

To study the effect of snowmelt timing on plant phenology, both natural (Kudo 1991; Kudo and Suzuki 1999; Sedlacek et al. 2015; Wheeler et al. 2015; Carbognani et al. 2016; Gehrmann et al. 2017) and experimental gradients of snowmelt timing (Henry and Molau 1997; Walker et al. 1999; Wipf and Rixen 2010; Cooper et al. 2011) have been used. However, both of these methods record responses at different temporal scales and feature their own set of advantages and limitations, which complicates intercomparison among methods and ultimately impedes development of a robust consensus on likely phenological responses to climate change to inform environmental policy and species distribution models (Dunne et al. 2004).

Natural gradients in snowmelt timing give information about the range of conditions plant populations can cope with under the current climate and this may give insight into the resilience of the population in the future (Gehrmann et al. 2017, 2020). Observations reflect the equilibrated responses of biotic communities, which have adapted over a long period to the local temperature and moisture regime. However, this method assumes that the variation over space elicits the same responses in plants as change over time and that biotic interactions remain the same as the climate changes, which is unlikely to be the case. Further, it remains difficult to completely remove, and (or) control for, the confounding 
effects of other environmental factors, which often co-vary with the factors of interest along the gradient (Dunne et al. 2004; Fukami and Wardle 2005).

Experimental manipulations of snowmelt timing and temperature, such as snow fences that passively accumulate snow during winter (Cooper et al. 2011), or open top chambers (OTCs) that passively warm the vegetation throughout the whole growing season, allow the establishment of possible causal relationships between the plant response and the treatment because specific controls are available. However, such broad manipulations alone cannot determine the role of specific primary drivers of autumn phenology, such as soil temperature under the snow or short-term, selective warming of the autumn season. Rather, they show the net effect of these climate conditions (Dunne et al. 2004). Furthermore, the initial response of plants to climatic changes may not correspond to the equilibrated response to long-term, sustained changes in climate. Therefore, short-term experiments may over- or under-predict the plant responses to climate change so that observations and experiments often give different results and lead to different conclusions (Leuzinger et al. 2011; Wolkovich et al. 2012; Blume-Werry et al. 2016a). Few studies have directly compared natural with experimental gradients, so it is difficult to predict how plant responses to gradients caused by natural environmental variations or experimental manipulations differ. Which approach is more relevant to understanding the impacts of anthropogenic climate change on plants depends on the speed and magnitude with which the climate will change. Overall, the limitations of each of these study methods imply that a combination of approaches is necessary to better understand plant responses to a changing climate.

Here, we combine natural and experimental gradients of snowmelt timing and selective warming during autumn senescence in the same site to study the long- and short-term effects of changes in snowmelt timing and the short-term effects of elevated temperature on the timing of autumn senescence. The experimental snowmelt gradient has been in place since 2006 whereas the natural snowmelt gradient is based on the local microtopography, providing significantly contrasting timescales of exposure. Furthermore, our selective experimental passive warming in autumn only allows us to examine the effects of elevated temperature specifically in the autumn period as observed and predicted across the Arctic (Chylek et al. 2009; Serreze et al. 2009), instead of passive warming across the whole growing season, as has been most commonly studied (e.g., Henry and Molau 1997). We hypothesise that

1. Experimental and natural gradients yield different conclusions on the effect of snowmelt timing on autumn senescence attributable to the different timescales and processes (adaptation vs. plasticity) involved.

2. Passive warming in autumn, rather than whole-growing-season warming, is sufficient to delay autumn senescence.

\section{Methods}

\section{Site description}

The field site is located in Adventdalen valley $\left(78^{\circ} 10^{\prime} \mathrm{N}, 16^{\circ} 06^{\prime} \mathrm{E}\right)$ on the High Arctic island of Spitsbergen in the Svalbard archipelago, where the polar day (no sunset) lasts from 19 April to 25 August. At the nearest weather station (Svalbard Airport), the annual mean temperature during the normal period (1991-2020) was $-3.9^{\circ} \mathrm{C}$ and mean temperatures during the coldest and warmest months were $-12{ }^{\circ} \mathrm{C}$ (March) and $7{ }^{\circ} \mathrm{C}$ (July), respectively (www.eklima.no). The mean annual precipitation during the same period is $217 \mathrm{~mm}$ with over $60 \%$ falling as snow, assuming precipitation falls as snow during October-May when the mean monthly temperature is below $0{ }^{\circ} \mathrm{C}$ (www.eklima.no). This constitutes a $2.8^{\circ} \mathrm{C}$ rise 
Fig. 1. Plot and sampling design of the study. (a) Three snow fences and three natural gradients were used in each vegetation type (Heath or Meadow). In each gradient, three plots were marked in a location with Low snow depth, three plots in a location with Medium snow depth, and three plots in a location with Deep snow depth. In the experimental gradients, the $L o w_{\exp }$ plots were located either at the windward side of the fence or next to the fence beyond the area of snow accumulation, while Medium $e_{\exp }$ and Deep $_{\text {exp }}$ were leeward. In each plot, five shoots per species were marked for observations (black dots). (b) In one of the natural gradient slopes, three open top chambers (OTCs; pentagons) were set up in each snow regime adjacent to the control plots (squares).

(a)

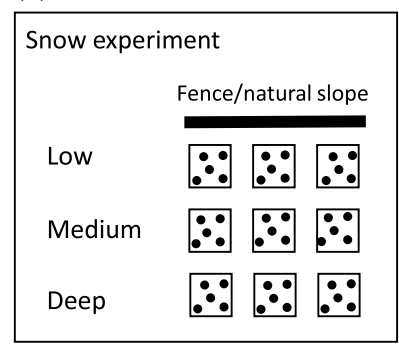

\begin{tabular}{lcccc}
\hline & \multicolumn{2}{c}{ Heath } & \multicolumn{2}{c}{ Meadow } \\
\hline & Experimental & Natural & Experimental & Natural \\
\hline $\begin{array}{l}\text { No. fences/ } \\
\text { natural slopes }\end{array}$ & 3 & 3 & 3 & 3 \\
$\begin{array}{l}\text { No. plots } \\
\text { Low }\end{array}$ & 9 & 9 & 9 & 9 \\
Medium & 9 & 9 & 9 & 9 \\
Deep & 9 & 9 & 9 & 9 \\
\hline
\end{tabular}

(b)

\begin{tabular}{|c|c|}
\hline \multicolumn{2}{|c|}{$\begin{array}{l}\text { OTC experiment } \\
\text { Natural slope }\end{array}$} \\
\hline \multicolumn{2}{|l|}{ Low } \\
\hline Mediu & $\left.\because 0^{\circ}\right\rangle$ \\
\hline Deep & \\
\hline
\end{tabular}

\begin{tabular}{lcc}
\hline & Natural - Control & Natural - OTC \\
\hline No. plots & 3 & 3 \\
Low & 3 & 3 \\
Medium & 3 & 3 \\
Deep & & \\
\hline
\end{tabular}

in mean annual temperature and a $27 \mathrm{~mm}$ rise in mean annual precipitation compared with the previous normal period (1961-1990, www.eklima.no). Locally, snow can be almost absent on ridges or reach up to $3 \mathrm{~m}$ depth in hollows due to the effect of wind and microtopography on snow deposition. Approximately $40 \%$ of Svalbard is covered by continuous permafrost, which has an active layer depth of $0.8-2.5 \mathrm{~m}$ (Humlum et al. 2003). The vegetation zones on Svalbard are polar desert and, to a lesser extent, Arctic tundra dominated by dwarf shrubs such as Cassiope tetragona (L.) D.Don, Salix polaris Wahlenb., and Dryas octopetala L., as well as graminoids. The study was carried out in two vegetation types that were found to have different soil moisture during the growing season (Cooper et al. 2011): dry heath ("Heath") and mesic meadow ("Meadow"). The Heath site was located at the foot of a mountain slope and was faster draining, while the Meadow site was located near a river basin and retained higher soil moisture until mid-July (Morgner et al. 2010; Cooper et al. 2011). Further description of the site is provided by Cooper et al. (2011).

\section{Snowmelt gradients}

Six experimental and six natural gradients of snowmelt timing were set up in the study area (Fig. 1a).

Three snow fences previously established in each of two vegetation types (Heath and Meadow sites) were used to create the six experimental gradients. The wooden fences were $1.5 \mathrm{~m}$ tall and $6.2 \mathrm{~m}$ long and were established in 2006 (Cooper et al. 2011). They were placed perpendicular to the prevailing wind direction (southeast), which caused an accumulation of snow on the lee side of the fence with different snow regimes 
(Supplementary Fig. S1 $a^{2}$ ). In the following, "snow regime" is referred to the combination of environmental conditions caused by the different snow depths, which includes variations in snowmelt timing, soil moisture, soil temperature, and nutrient availability. Snow regime was therefore treated here as an "umbrella" environmental factor that combines the effects of these other conditions. Three $75 \mathrm{~cm} \times 75 \mathrm{~cm}$ plots were marked between 2 and $14 \mathrm{~m}$ on the leeward side of the fence in the area with the deepest snow accumulation ("Deep exp"). An additional three plots were marked between 11 and $26 \mathrm{~m}$ on the leeward side of the fence with medium accumulation of snow ("Medium exp"). Three plots with ambient snow regime ("Low $w_{\text {exp }}$ ) were marked in the vicinity of each fence, either on the windward side of the fence or next to the fences beyond the area of snow accumulation.

In July 2016, six natural gradients (three in each vegetation type) of three snow regimes with different snow depth and snowmelt timing were defined according to the local microtopography within approximately $50 \mathrm{~m}$ of the fences. Along microelevational gradients in the landscape (ca. 1 to $3 \mathrm{~m}$ vertical height), three plots were set up at the top of the slope where little snow accumulates and therefore melts early ("Low ${ }_{\text {nat }}$ "), three plots were installed along the slopes with medium snow accumulation and moderate snowmelt timing ("Medium nat"), and three plots were placed at the foot of the slopes where snow accumulates the most and therefore melts late ("Deep nat"; Supplementary Fig. S1b"). The Low $w_{\text {nat }}$ plots in two of the natural gradients in the Heath site were the same as the Low exp plots in the two closest experimental gradients. The third natural gradient had its own set of Low $w_{\text {nat }}$ plots.

On 4 April 2017, snow depth behind each snow fence of the experimental gradient was measured along three parallel $18 \mathrm{~m}$ long transects in $2 \mathrm{~m}$ intervals starting at $1.5 \mathrm{~m}$ away from the fences. The approximate snow depth in each Deep exp $_{\text {and }}$ aedium $m_{\text {exp }}$ plot was then estimated from their known location behind the fence. Snow depth over the winter period 2016-2017 in the Lowexp plots of the experimental gradient and all plots of the natural gradient was measured at marking sticks that had been left in the ground during the snow-free period near the plots. Ground ice was common in the area especially in places with little snow cover and was estimated to be up to $10 \mathrm{~cm}$ in some locations.

\section{OTC set-up}

In one of the three natural gradients in the Heath site, three five-sided OTCs (height = $0.5 \mathrm{~m}$, surface area $=2.56 \mathrm{~m}^{2}$ ) made of Plexiglas (Henry and Molau 1997; Marion et al. 1997) were installed in each snow regime (Low nat $_{\text {, }}$ Medium $_{\text {nat }}$, and Deep nat ), with each OTC adjacent to one of each of the natural gradient plots (see above), on 20 July 2016 and removed at the end of the experiment on 7 August 2016. The Low nat $_{\text {, Medium }}$ nat, and Deep nat plots of the natural snowmelt gradient (see above) were used as control plots. The OTC installation took place shortly before the beginning of visible leaf colouration associated with autumn senescence, which coincides with a sharp decline in biomass production (Blume-Werry et al. 2016b), so we selectively increased the temperature at the end of the growing season.

\section{Temperature and soil moisture measurements}

Air temperatures at approximately $20 \mathrm{~cm}$ above the ground were measured at hourly intervals from 23 July 2016 until 7 August 2016 with iButtons (DS1922L-F5 thermochrons; Homechip Ltd., Milton Keynes, UK) in one or two plots in each snow treatment of the 12 individual gradients, as well as in the centre of six of the OTCs. Air temperature loggers were shaded from direct insolation with white plastic cups $(9 \mathrm{~cm}$ tall and $7.5 \mathrm{~cm}$ diameter

\footnotetext{
${ }^{2}$ Supplementary data are available with the article at https://doi.org/10.1139/as-2020-0044.
} 
at the widest end) placed on top of the loggers. Several cuts of $6 \mathrm{~cm}$ length and spaced $2 \mathrm{~cm}$ apart were made lengthwise into the cups to improve ventilation.

Soil surface temperatures were measured at hourly intervals from 23 July 2016 until summer 2017 with iButtons (DS1922L-F5 thermochrons; Homechip Ltd., Milton Keynes, UK). Of the soil temperature loggers, $47 \%$ stopped functioning over the subsequent winter, so the closest functioning loggers were used as a temperature estimate for the determination of snowmelt timing. In different locations of the experimental gradient, the soil surface temperature had been logged additionally with Tinytag (Gemini Data Loggers, Chichester, UK) temperature loggers at hourly intervals for several years before and including the present study.

Snowmelt timing in 2017 was estimated from both types of loggers in the experimental gradient and from the iButtons in the natural gradient as the day on which the soil surface temperature started fluctuating above $0{ }^{\circ} \mathrm{C}$. The correlation of snowmelt timing as estimated from the two loggers in the experimental gradient $(R=0.91)$ in 2017 was used to estimate snowmelt timing in the experimental gradient in 2016. The correlation of snowmelt timing between the experimental and natural gradients as estimated from the iButtons $(R=0.8)$ was used to estimate snowmelt timing in the natural gradient in 2016.

Soil moisture was measured on the same days as observations of phenology and normalised difference vegetation index (NDVI) measurements (see next sections) with a Theta ML 2x probe (Delta-T Devices Ltd., Cambridge, UK) in three locations per plot.

\section{Observation of autumn senescence}

Observations of autumn phenology were made on the dwarf shrub S. polaris, the evergreen dwarf shrub D. octopetala, and the herbaceous species Bistorta vivipara (L.) Delarbre and Oxyria digyna (L.) Hill. In each plot, five individual shoots per species were loosely marked with a cable tie or string. Bistorta vivipara was present in all marked plots and S. polaris in all plots but one. Oxyria digyna was not sufficiently present in the Meadow site, so only data from the Heath site were included in this study. Oxyria digyna and D. octopetala were lacking in about $20 \%$ of all studied plots, but there was only one of the six natural and one of the six experimental gradients in which they were lacking completely from a whole snowmelt group.

The onset of autumn senescence was defined as the first day on which any amount of autumn colouration (yellow in S. polaris and D. octopetala, brown or yellow in Bistorta vivipara, and red in 0 . digyna) was visible on at least one leaf (the top leaf in D. octopetala) of the marked shoot. In this study, we chose the onset of senescence as the first and most distinguishable sign of senescence. It is also the easiest to consistently and objectively compare between different observers. The shoots were observed every other day from 19 July 2016 (in OTCs: 20 July and 23 July, then every other day) to 6 August 2016 and the date of onset of autumn senescence was noted down for each marked shoot. Additionally, the timing of autumn senescence was calculated as the number of days after snowmelt (DAS) until the onset of senescence by subtracting the day of year (number of days from 1 January; DOY) from day of year of snowmelt. No noticeable amount of leaf colouration was seen in the study area at the beginning of the observation period. By the end of the study period, $90 \%$ of all individuals had started to senesce. The remaining individuals were excluded from the analysis in order to focus the analysis on when senescence occurred rather than whether it occurred during the study period.

\section{NDVI measurement}

On the same days as the phenological observations, the average NDVI index (calculated from the red and near-infrared light reflected by vegetation) was measured on each plot 
with a GreenSeeker handheld optical crop sensor (Trimble Inc., Sunnyvale, California, USA) as a measure of vegetation greenness. The GreenSeeker was held at approximately $120 \mathrm{~cm}$ height and moved horizontally across each plot to give an average reading of a $50 \mathrm{~cm}$ oval area on the ground.

\section{Statistical analysis}

The effects of vegetation type (Heath or Meadow), snow regime (Lownat, Medium ${ }_{\text {nat }}$, or Deep $_{\text {nat }}$ in the natural gradient; $L_{\text {oxp }}$, Medium exp $_{\text {, or Deep }}$ exp in the experimental gradient), and OTC treatment (control or OTC) on the DOY of autumn senescence and on the NDVI were analysed separately for each gradient type (natural or experimental) and separately for each species (in the DOY analysis) with a linear mixed-effects model using the nlme package (Pinheiro et al. 2020, version 3.1-137) in $R$ ( $R$ Core Team 2020, version 3.5.1). In the snowmelt gradient study, the DAS was additionally analysed as a response variable. The fixed effects were snow regime and vegetation type and the random effect Plot nested in Fence. The sample size in the DAS analysis was lower because the day of year of snowmelt was not available for some plots in the natural gradient. No analysis was carried out for DAS in 0. digyna in the natural gradient due to the low sample size. In the OTC study, the fixed effects were snow regime and OTC treatment and the random effect was Plot, because only a single gradient was used. Model selection was carried out using the maximum likelihood test and significance of predictor variables $(p \leq 0.05)$ was determined with $F$ tests. Residuals were checked visually for compliance with assumptions of normality of the residual distribution, homogeneity of residual variance, and independency of observations. Pairwise comparisons were carried out with the emmeans package in $\mathrm{R}$ (Lenth et al. 2019, version 1.3.0). When pairwise comparisons were significant, the $p$ value was adjusted using the Holm's method.

The difference in mean soil moisture between Vegetation types and Snow regime, and their interaction, was tested for significance $(p \leq 0.05)$ with a linear mixed-effects model using Plot nested in Fence as a random effect. Residuals were checked visually for compliance with ANOVA assumptions.

Figures 2-7 were prepared in R (version 3.6.2) and Fig. 1 was prepared in Powerpoint.

\section{Results}

\section{Comparison of experimental and natural snowmelt gradients}

Snow depth was greater and more variable along the experimental compared with the natural gradient (Table 1). In the experimental gradient, Deep $p_{\exp }$ plots accumulated $1.1 \pm 0.04 \mathrm{~m}$ (mean $\pm \mathrm{SE})$ of snow and Medium ${ }_{\text {exp }}$ plots accumulated $0.6 \pm 0.07 \mathrm{~m}$. Low $_{\text {exp }}$ plots were covered by between 0.1 and $0.5 \mathrm{~m}$ of snow (measured approximately). In the natural gradient, the snow depth in Low $_{\text {nat }}$ plots was approximately $0-0.1 \mathrm{~m}$, in Medium nat $_{\text {plots }}$ 0.1-0.2 m, and in Deep nat plots 0.3-0.5 m. Hence, when considering snow depth, Medium exp $_{\text {, }}$ plots in the experimental snow gradient were more similar to Deep nat plots, rather than Medium $_{\text {nat }}$ plots, in the natural snow gradient.

In the experimental treatment, Low $w_{\exp }$ plots melted out on 24-26 May, Medium exp $_{\text {plots on }}$ 4-5 June, and Deep $p_{\text {exp }}$ plots on 10-12 June 2016. Despite the differences in snow depth between the experimental and the natural snowmelt gradients, snowmelt timing in the experimental gradient was similar in the corresponding plots of the natural gradient (Table 1), i.e., Low $_{\text {exp }}-$ Low $_{\text {nat }}$, Medium exp - Medium $_{\text {nat }}$, and Deep exp $^{-}$Deep $p_{\text {nat }}$ had similar snowmelt timing.

Soil moisture varied significantly with snowmelt timing $\left(\right.$ Snow $_{\text {exp }}: F_{[2,1568]}=10.34$, $p<0.0001$; Snow $\left.{ }_{\text {nat }}: F_{[2,1597]}=45.61, p<0.0001\right)$ but not with Vegetation type, so Vegetation type did not represent different soil moisture conditions during the autumn. In the 
Fig. 2. Volumetric water content (VWC, \%) in an experimental $\left(\right.$ Low $_{\exp }=$ solid line, Medium $_{\exp }=$ dotted line, Deep $_{\exp }=$ dashed line) and natural (Low nat $=$ solid line, Medium $_{\text {nat }}=$ dotted line, Deep $_{\text {nat }}=$ dashed line $)$ snowmelt gradient at two different vegetation types (Heath and Meadow). VWC was measured every other day from 19 July to 7 August 2016 $(n=9)$. DOY, day of year.

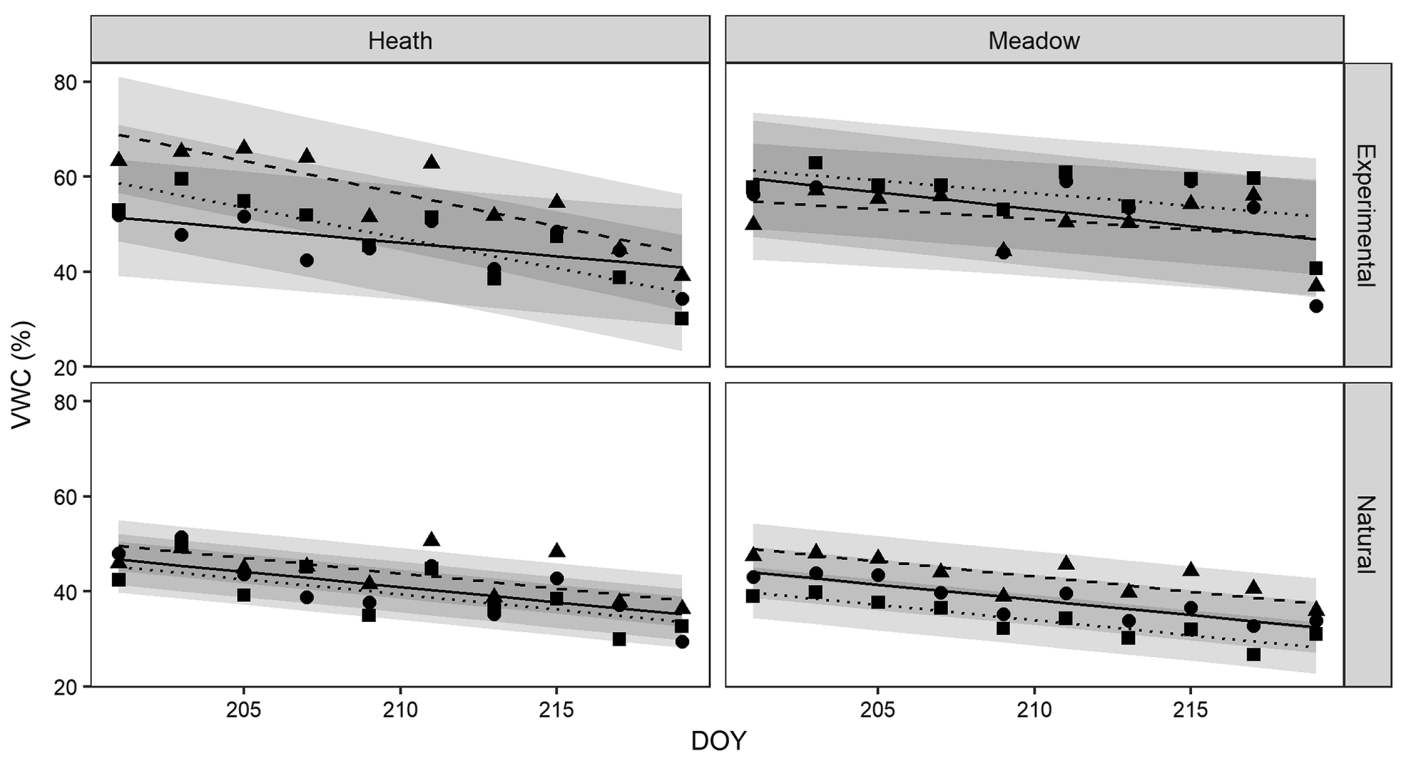

Fig. 3. The mean day of year (DOY \pm SE) of the onset of senescence in (a) Salix polaris, (b) Bistorta vivipara, (c) Dryas octopetala, and (d) Oxyria digyna along an experimental $\left(\right.$ Low $_{\text {exp }}$, Medium exp $_{\text {, Deep }}$ exp $)$ and natural $\left(\right.$ Low $_{\text {nat }}$, Medium $_{\text {nat }}$, Deep $\left._{n a t}\right)$ snowmelt gradient. Different letters below the data points indicate significant different means between snow regimes within the same species and snowmelt gradient. Vegetation type only had a significant effect on senescence in $S$. polaris growing in the natural gradient. Data for senescence timing along the snow regimes are therefore presented as means across both vegetation types. n.s., not significant.
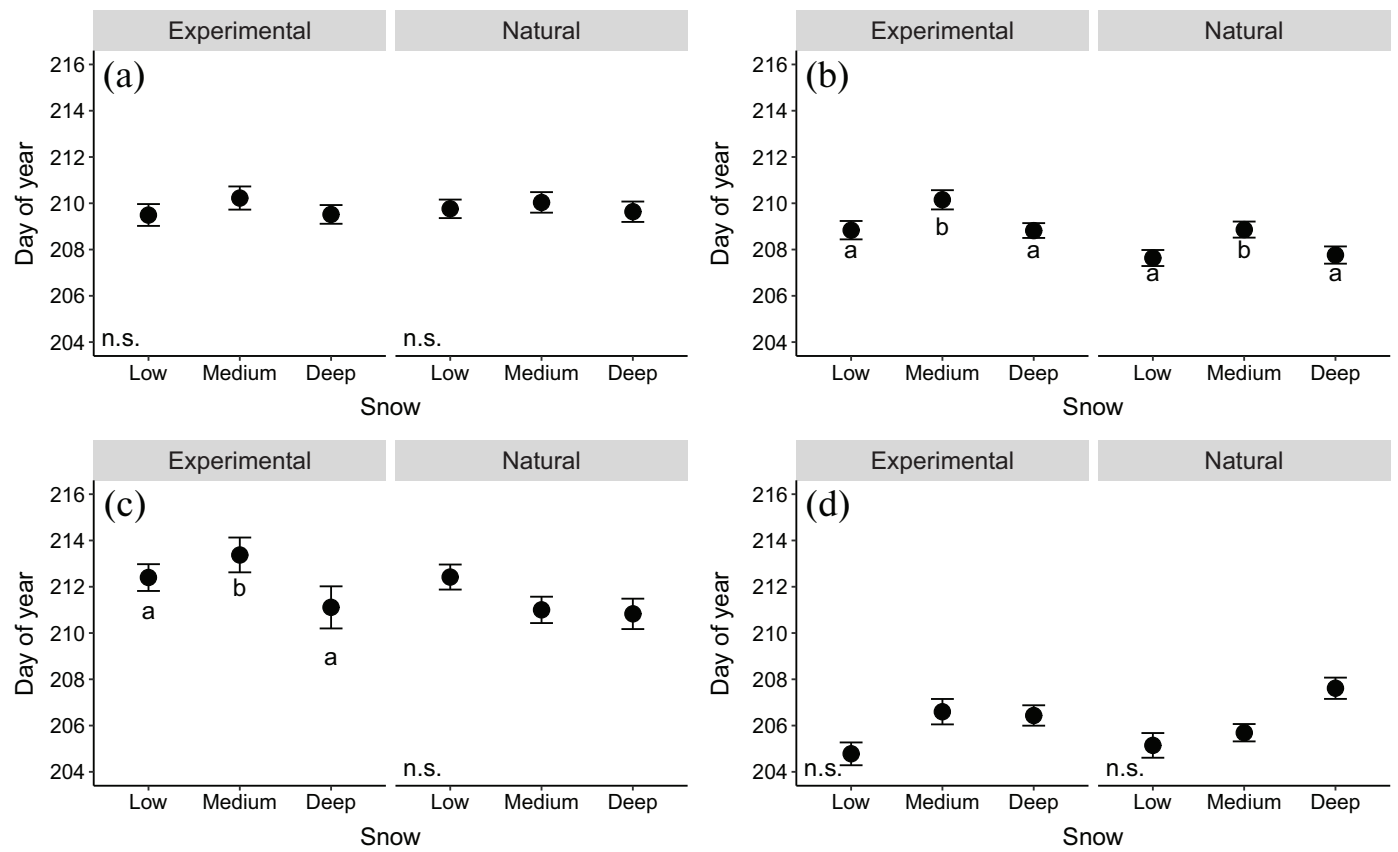

- Published by Canadian Science Publishing 
Fig. 4. The mean number of days after snowmelt $( \pm \mathrm{SE})$ of the onset of senescence in (a) Salix polaris, (b) Bistorta vivipara, (c) Dryas octopetala, and (d) Oxyria digyna along an experimental (Low exp $_{\text {, Medium }}$ exp $_{\text {, Deep }}$ exp) and natural $\left(\right.$ Low $_{\text {nat }}$, Medium $_{\text {nat }}$, Deep $\left.{ }_{\text {nat }}\right)$ snowmelt gradient in two different vegetation types $($ Heath $=$ circle, Meadow $=$ triangle). Different letters denote significant differences between snow regimes (lowercase letters for the Heath site and uppercase letters for the Meadow site). No statistical testing was carried out for 0 . digyna due to the low sample size.
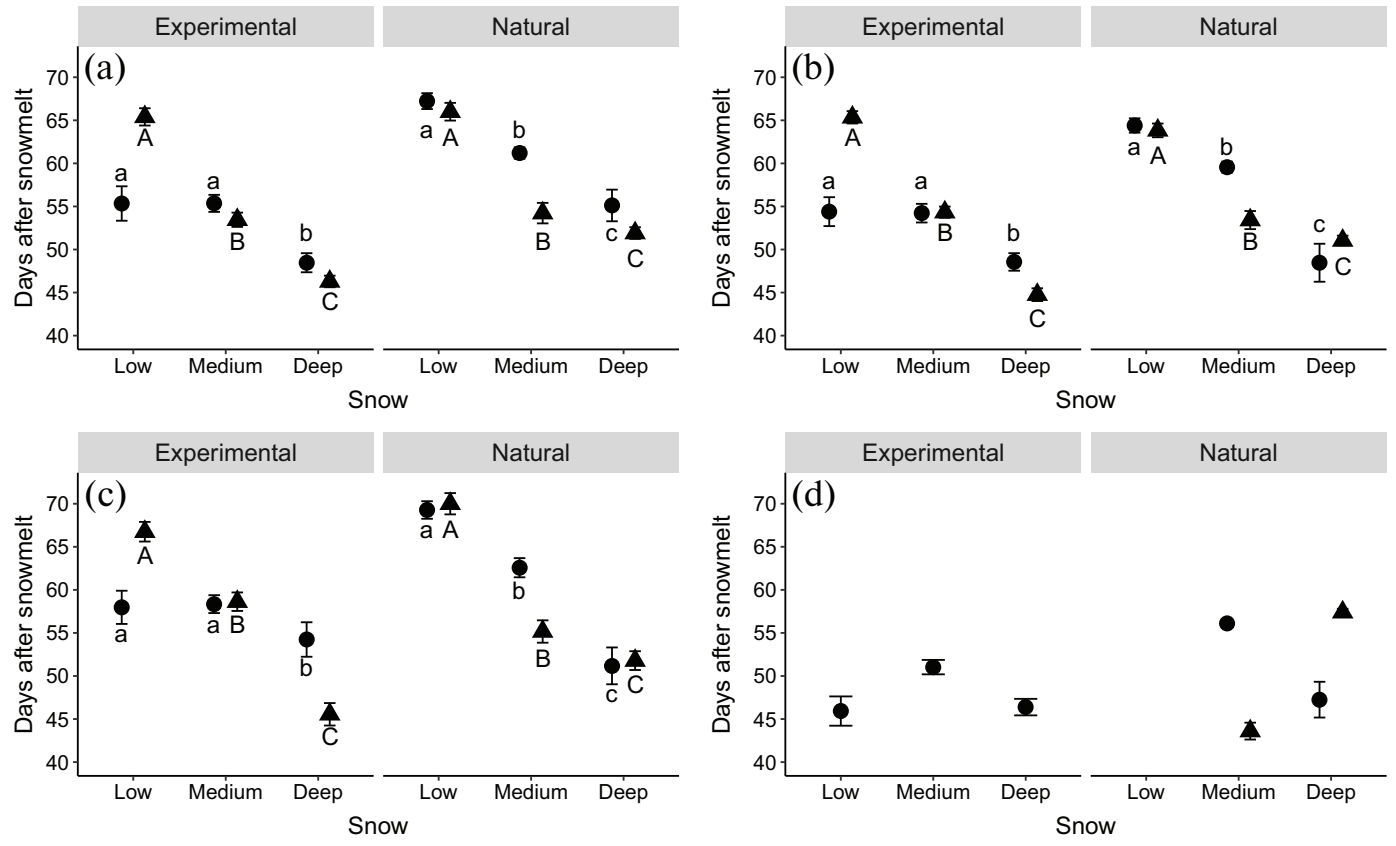

Fig. 5. The mean day of year $( \pm$ SE) of the onset of autumn senescence in four Arctic species (Bistorta vivipara, Dryas octopetala, Oxyria digyna, Salix polaris) along a snowmelt gradient in control (filled symbols) and open top chamber (OTC, open symbols) treatment plots. Different letters denote statistically different means. n.s., not significant.

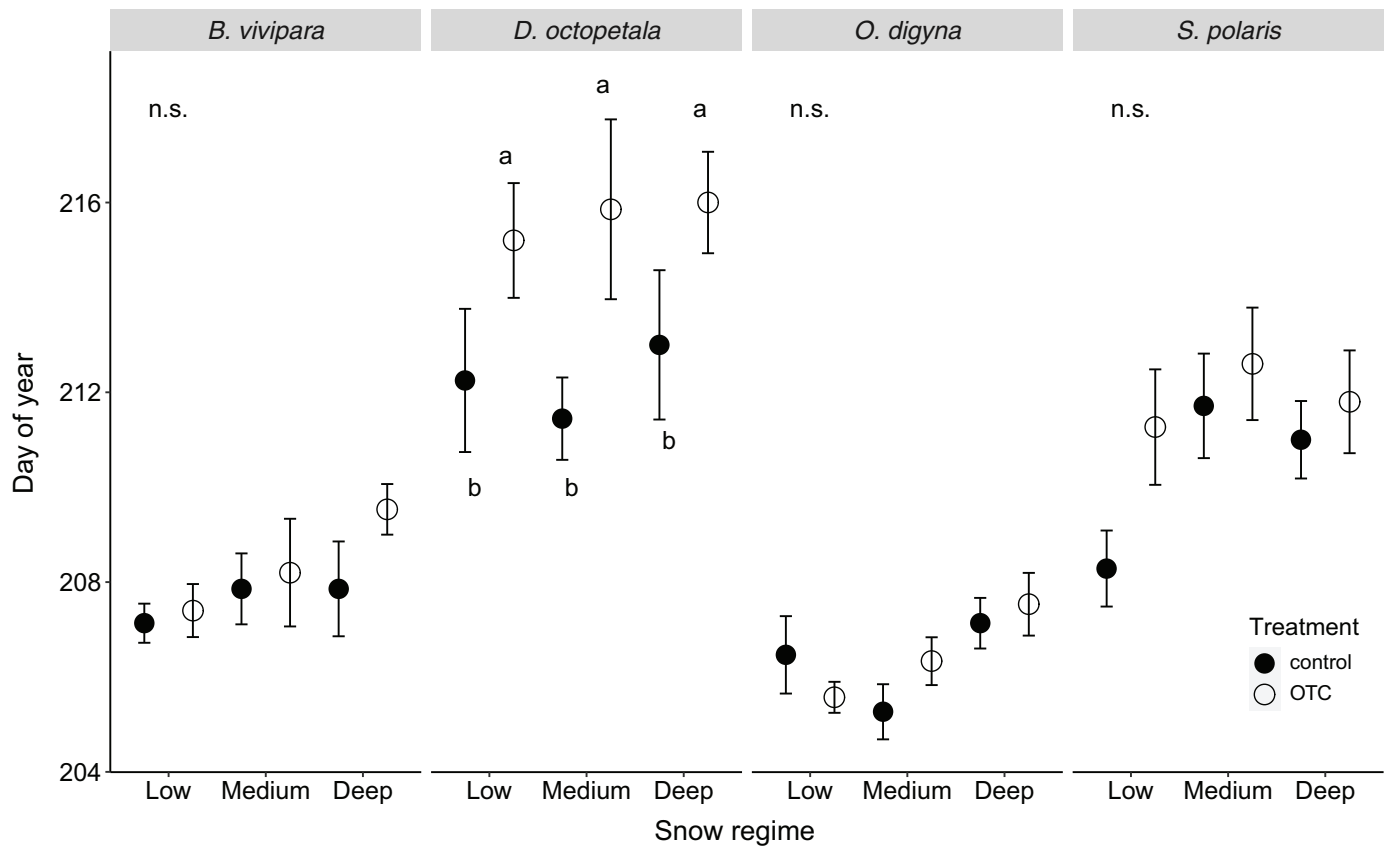

Published by Canadian Science Publishing 
Fig. 6. The accumulated number of marked senescing Dryas octopetala shoots for each observational day of year in control (black line) and open top chamber (grey line) plots.

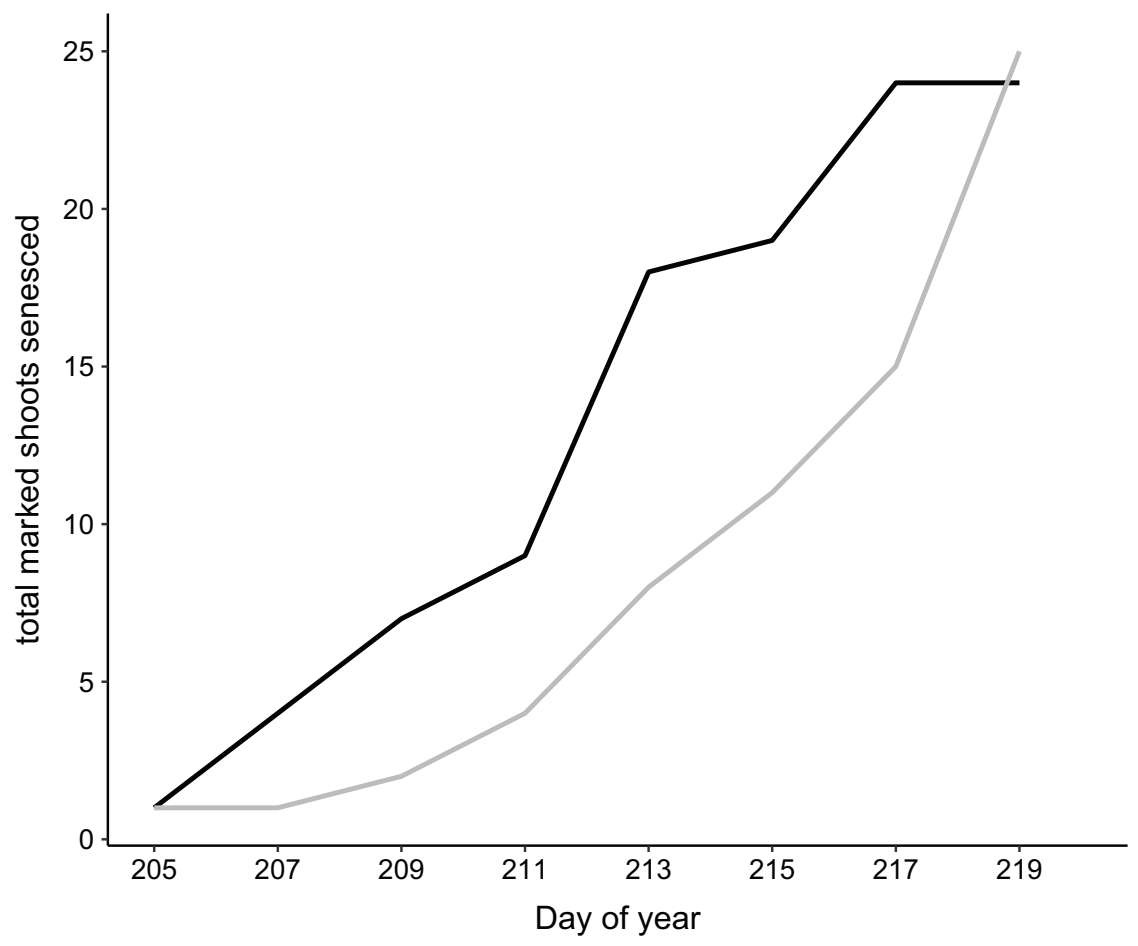

experimental gradient, soil moisture was lowest in Low $w_{\text {exp }}$ and highest in Deep exp $_{\text {(Table 2, }}$ Fig. 2). In the natural gradient, it was highest in Deep nat $_{\text {and }}$ anest in Medium nat $_{\text {. }}$

The effect of snow regime on autumn senescence

Oxyria digyna senesced first (DOY $=206 \pm 0.3$ (mean $\pm \mathrm{SE})$ ), followed by Bistorta vivipara $(\mathrm{DOY}=209 \pm 0.2), S$. polaris (DOY $=210 \pm 0.2$ ), and lastly D. octopetala (DOY $=212 \pm 0.3)$ (Fig. 3).

The effect of snow regime on the timing of senescence was the same in the experimental and the natural gradient in S. polaris, Bistorta vivipara, and 0 . digyna and different in D. octopetala. In S. polaris, snow regime had no significant effect on the timing of senescence onset in either gradient (Table 3, Fig. 3a). In Bistorta vivipara, senescence was significantly delayed

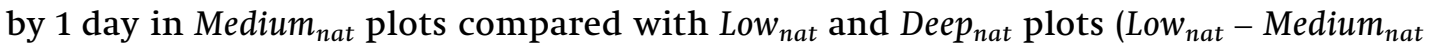
$p=0.04$, Deep $_{\text {nat }}-$ Medium $_{\text {nat }} p=0.04$ ) in the natural gradient and by 2 days in Medium exp $_{\text {plots }}$ compared with Low exp $_{\text {and }}$ Deep $p_{\text {exp }}$ plots in the experimental gradient (Low exp $_{\text {- Medium }}$ exp $p=0.0428$, Deep exp - Medium $_{\text {exp }} p=0.0428$; Fig. 3b). In D. octopetala, the snow regime only altered senescence timing significantly in the experimental gradient in the Meadow site

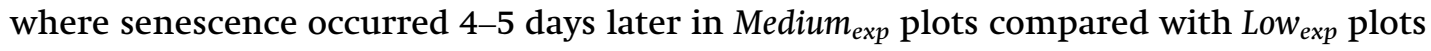
$(p=0.03)$ or Deep exp $_{p}$ plots $(p=0.01$; Fig. 3c). Senescence timing did not differ along the natural gradient in this species. Oxyria digyna was only present in both the experimental and the natural gradient in the Heath site where its senescence timing was not significantly affected by snow regime (Fig. 3d).

Vegetation type only had a significant effect on senescence in $S$. polaris growing in the natural gradient where it senesced 1.6 days earlier in the Meadow compared with the 
Fig. 7. Mean normalised difference vegetation index (NDVI) values and modelled regression with $95 \%$ confidence

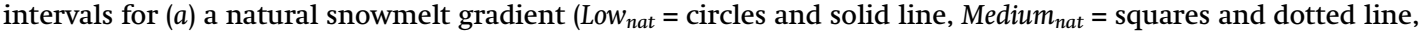
Deep $_{n a t}=$ triangles and dashed line) and $(b)$ an experimental snowmelt gradient ( Low $_{\text {exp }}=$ circles and solid line, Medium $_{\text {exp }}=$ squares and dotted line, Deep $_{\exp }=$ triangles and dashed line) in two vegetation types as well as for (c) control and open top chamber (OTC) treatment plots along one natural snowmelt gradient $\left(\right.$ Low $_{\text {nat }}=$ circles and solid line, Medium $_{\text {nat }}=$ squares and dotted line, Deep $_{n a t}=$ triangles and dashed line) in Heath.
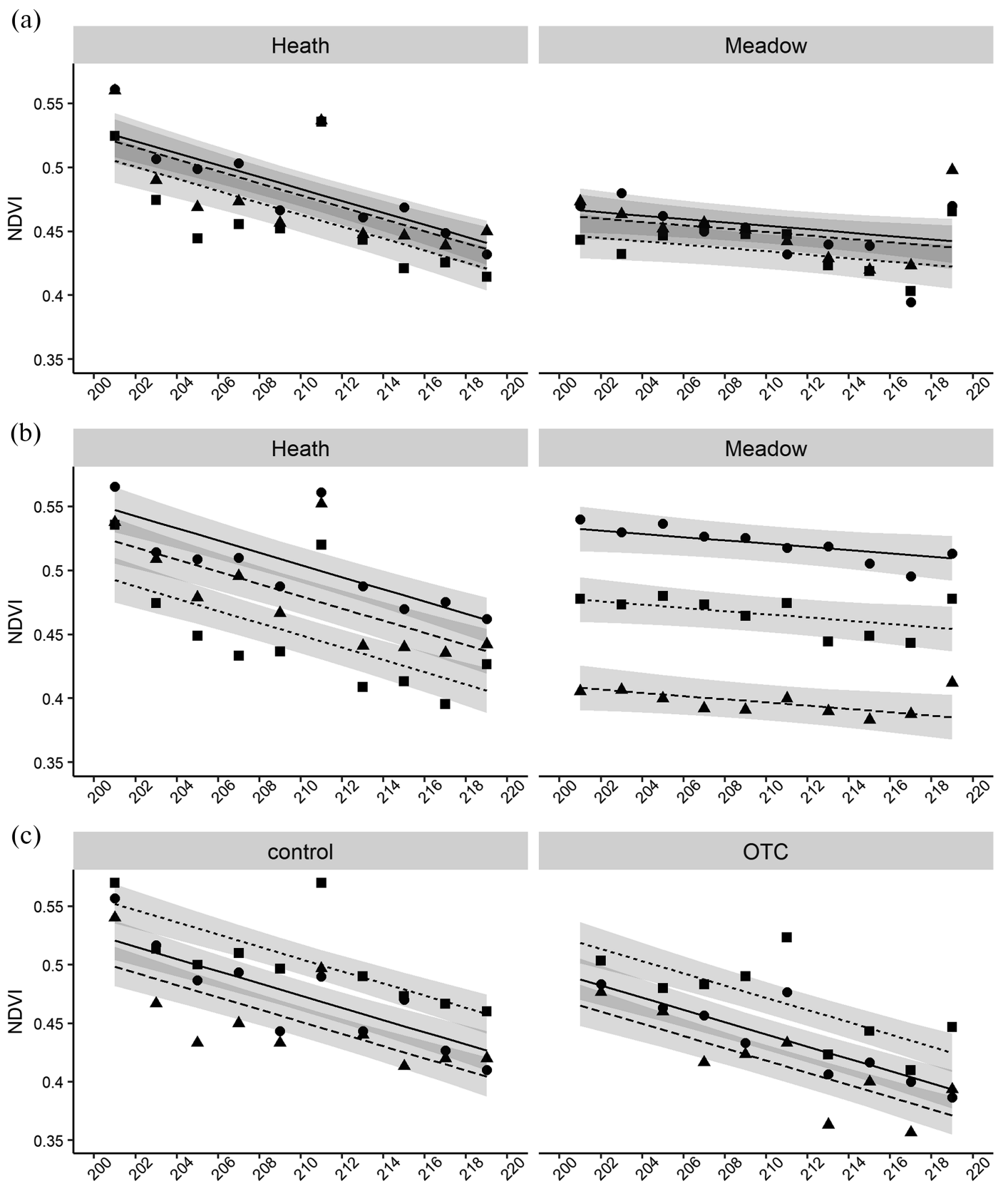

Day of year 
Table 1. Estimated date of snowmelt (day of year in parentheses) in 2016 and snow depth on 4 April 2017 along an experimental and a natural snowmelt gradient in two different vegetation types $(n=9)$.

\begin{tabular}{lllcc}
\hline Gradient & Vegetation & Low & Medium & Deep \\
\hline Experimental & Heath & 21 May 2016 (142) & 3 June 2016 (155) & 8 June 2016 (160) \\
& & $0.1-0.5 \mathrm{~m}$ & $0.7 \pm 0.2 \mathrm{~m}$ & $1.2 \pm 0.2 \mathrm{~m}$ \\
& Meadow & 23 May 2016 (144) & 4 June 2016 (156) & 12 June 2016 (164) \\
& & $0.1-0.5 \mathrm{~m}$ & $0.5 \pm 0.3 \mathrm{~m}$ & $1.1 \pm 0.2 \mathrm{~m}$ \\
Natural & Heath & 22 May 2016 (143) & 29 May 2016 (150) & 9 June 2016 (161) \\
& & $0-0.1 \mathrm{~m}$ & $0.1-0.2 \mathrm{~m}$ & $0.3-0.5 \mathrm{~m}$ \\
& Meadow & 22 May 2016 (143) & 3 June 2016 (155) & 4 June 2016 (156) \\
& & $0-0.1 \mathrm{~m}$ & $0.1-0.2 \mathrm{~m}$ & $0.3-0.5 \mathrm{~m}$ \\
\hline
\end{tabular}

Table 2. Pairwise comparisons (effect size, standard error (SE), degrees of freedom (df), $t$ ratio, and $p$ value of comparisons between plots with different snow regimes) of mean volumetric water content during the measuring period (19 July - 7 August 2016) between snow regimes in an experimental and a natural snowmelt gradient.

\begin{tabular}{lcccrr}
\hline Comparison & Effect size & SE & df & $t$ ratio & \multicolumn{1}{c}{$p$} \\
\hline Experimental gradient & -2.13 & 0.826 & 2,1568 & -2.529 & 0.0115 \\
Low-Medium & -4.06 & 0.827 & 2,1568 & -4.827 & $<0.0001$ \\
Low-Deep & 1.94 & 0.818 & 2,1568 & 2.326 & 0.0201 \\
Deep-Medium & & & & & \\
Natural gradient & & & & \\
Low-Medium & 2.94 & 0.719 & 2,1597 & 4.086 & $<0.0001$ \\
Low-Deep & -3.91 & 0.719 & 2,1597 & -5.434 & $<0.0001$ \\
Deep-Medium & 6.85 & 0.719 & 2,1597 & 9.520 & $<0.0001$ \\
\hline
\end{tabular}

Heath site (Table 3). Data for senescence timing along the snow regimes are therefore presented as means across both vegetation types in Fig. 3.

The effect of snow regime and vegetation type on the time from snowmelt until the onset of senescence (DAS) was similar among S. polaris, Bistorta vivipara, and D. octopetala (Figs. $4 a, 4 b, 4 c$ ). In these species, later snowmelt timing always significantly decreased the DAS (Table 4). This effect was significantly influenced by Vegetation type in the experimental gradient, where DAS was similar in Low exp $_{\text {and Medium }}$ exp plots in the Heath site but Low $_{\text {exp }}$ was significantly higher than Medium exp $_{\text {in }}$ the Meadow site (Table 4). In 0. digyna, no clear trend in the effect of Snow or Vegetation on DAS could be seen (Fig. 4d).

\section{The effect of passive autumn warming on the timing of autumn senescence}

The OTCs caused an average increase in air temperature of $1{ }^{\circ} \mathrm{C}$ between 23 July (DOY 205) and 6 August 2016 (DOY 2019) (Supplementary Fig. S2 ${ }^{2}$ ). At night, temperatures between OTC and control plots were similar, but during daytime, the OTC plots were heated by up to $8{ }^{\circ} \mathrm{C}$ compared with the temperature in the control plots. This is likely due to additional heating effects from direct insolation or rising warm air from the soil, as the actual temperature during those periods of very high warming greatly exceeded the temperature measured at the weather station (Appendix A). Removing any temperatures above $18{ }^{\circ} \mathrm{C}$ (considering the maximum weather station temperature was $13.4{ }^{\circ} \mathrm{C}$ ) yielded a maximum temperature increase of $5{ }^{\circ} \mathrm{C}$ for OTC plots. It is worth noting that although wind reduction inside OTCs has previously not been found to be the driver of air temperature (Bokhorst et al. 2013), the effect it has on the boundary layer of plants can cause large differences in plant tissue surface temperature inside OTCs 
Table 3. The effect of Snow regime (Low, Medium, Deep) and Vegetation type (Heath, Meadow) on the day of year of the onset of autumn senescence in four High Arctic plant species growing along an experimental and a natural snowmelt gradient.

\begin{tabular}{llll}
\hline & Snow & Vegetation & Snow $\times$ Vegetation \\
\hline $\begin{array}{llll}\text { S. polaris } \\
\text { Experimental gradient }\end{array}$ & n.s. & n.s. & n.s \\
$\begin{array}{l}\text { Natural gradient } \\
\text { Bistorta vivipara }\end{array}$ & n.s. & $F_{[1,4]}=9.5, p=0.037$ & n.s. \\
$\begin{array}{l}\text { Experimental gradient } \\
\text { Natural gradient }\end{array}$ & $F_{[2,46]}=3.7, p=0.0332$ & n.s. & n.s. \\
$\begin{array}{ll}\text { D. octopetala } \\
\text { Experimental gradient }\end{array}$ & $F_{[2,46]}=3.5, p=0.0386$ & n.s. & n.s. \\
$\begin{array}{l}\text { Natural gradient } \\
\text { O. digyna }\end{array}$ & n.s. & & \\
Experimental gradient & n.s. & n.s. & $F_{[2,31]}=3.15, p=0.0571$ \\
Natural gradient & n.s. & & n.s. \\
\hline
\end{tabular}

Note: The results of the F statistics from the ANOVA are shown. NA, lack of statistical testing due to insufficient representation of plants within study plots; n.s., not significant.

Table 4. The effect of Snow regime (Low, Medium, Deep) and Vegetation type (Heath, Meadow) on the days after snowmelt until the onset of autumn senescence in four High Arctic plant species growing along an experimental and a natural snowmelt gradient.

\begin{tabular}{llll}
\hline & Snow & Vegetation & Snow $\times$ Vegetation \\
\hline $\begin{array}{l}\text { S. polaris } \\
\text { Experimental gradient }\end{array}$ & $F_{[2,43]}=25.06, p<0.0001$ & n.s. & $F_{[2,43]}=6.33, p=0.0039$ \\
$\begin{array}{l}\text { Natural gradient } \\
\text { Bistorta vivipara }\end{array}$ & $F_{[2,29]}=14.75, p<0.0001$ & n.s. & n.s. \\
$\begin{array}{l}\text { Experimental gradient } \\
\text { Natural gradient }\end{array}$ & $F_{[2,44]}=32.65, p<0.0001$ & n.s. & $F_{[2,44]}=10.57, p=0.0002$ \\
$\begin{array}{l}\text { D. octopetala } \\
\text { Experimental gradient }\end{array}$ & $F_{[2,27]}=35.73, p<0.0001$ & n.s. & $F_{[2,27]}=7.29, p=0.0029$ \\
$\begin{array}{l}\text { Natural gradient } \\
\text { o. digyna }\end{array}$ & $F_{[2,138]}=54.27, p<0.0001$ & n.s. & $F_{[2,138]}=18.23, p<0.0001$ \\
Experimental gradient & $F_{[2,16]}=7.2, p=0.0059$ & NA & NA \\
Natural gradient & NA & NA & NA \\
\hline
\end{tabular}

Note: The results of the $F$ statistics from the ANOVA are shown. NA, lack of statistical testing due to missing or low sample size; n.s., not significant.

(De Boeck et al. 2012). The passive warming effect was stronger in the Low $w_{\text {nat }}$ than in Medium $_{n a t}$ and Deep nat $_{\text {. The soil surface temperature within the OTCs was colder in Low }}$ nat

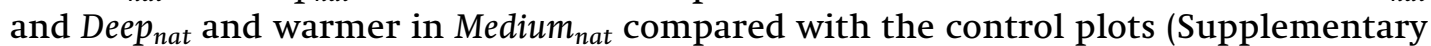
Fig. S2 $b^{2}$, Appendix A). Both cooling and warming effects of soil surface temperature due to OTCs have been reported previously and can be due to water logging, plant cover, and microsite placement of the loggers (Hollister et al. 2006). In future studies, more temperature loggers and their more careful placement could achieve clearer results.

The OTCs caused an overall delay of 1.5 days in the autumn senescence across all species $\left(F_{[1,14]}=8.3, p=0.012\right.$; Fig. 5$)$. This was mostly due to D. octopetala, which senesced 3.7 days later in plots with the OTC treatment $(p=0.0014)$, while the other species had no significant delay in the timing of senescence. The effect of the OTCs was the same across all snowmelt regimes. The first signs of senescence in the tagged shoots appeared later in the OTC treatment compared with the control and most individuals senesced at the end of the 
Table 5. Pairwise comparisons (effect size, standard error (SE), degrees of freedom (df), $t$ ratio, and $p$ value of comparisons between plots with different snow regimes; $n=9$ ) of normalised difference vegetation index between snow regimes in an experimental and a natural snowmelt gradient in two different vegetation types (Heath and Meadow).

\begin{tabular}{|c|c|c|c|c|c|c|c|c|c|c|}
\hline \multirow[b]{2}{*}{ Comparison } & \multicolumn{5}{|l|}{ Heath } & \multicolumn{5}{|l|}{ Meadow } \\
\hline & $\begin{array}{l}\text { Effect } \\
\text { size }\end{array}$ & SE & df & $t$ ratio & $p$ & $\begin{array}{l}\text { Effect } \\
\text { size }\end{array}$ & SE & df & $t$ ratio & $p$ \\
\hline \multicolumn{11}{|c|}{ Natural gradient } \\
\hline Low-Medium & 0.02 & 0.006 & 5,530 & 3.369 & 0.0032 & 0.02 & 0.006 & 5,530 & 3.369 & 0.0032 \\
\hline Low-Deep & 0.005 & 0.006 & 5,530 & 0.819 & 0.4 & 0.005 & 0.006 & 5,530 & 0.819 & 0.4 \\
\hline Medium-Deep & 0.015 & 0.006 & 5,530 & 2.550 & 0.02 & 0.015 & 0.006 & 5,530 & 2.550 & 0.02 \\
\hline \multicolumn{11}{|c|}{ Experimental gradient } \\
\hline Low-Medium & 0.055 & 0.009 & 4,528 & 6.411 & 0.0006 & 0.055 & 0.009 & 4,528 & 6.437 & 0.0006 \\
\hline Low-Deep & 0.024 & 0.009 & 4,528 & 2.849 & 0.0046 & 0.124 & 0.009 & 4,528 & 14.467 & 0.0006 \\
\hline Medium-Deep & 0.031 & 0.009 & 4,528 & 3.562 & 0.0008 & -0.069 & 0.009 & 4,528 & -8.03 & 0.0006 \\
\hline
\end{tabular}

Note: $p$ values were adjusted using the Holm's method.

observation period compared with the control plants for which there was a peak in senescence on DOY 213 (Fig. 6).

\section{The effect of snow regime and temperature on NDVI}

In both the experimental and the natural gradients, there was a significant decline in NDVI (DOY exp $: F_{[1,528]}=49.39, p<0.0001$; DOY nat $\left._{\text {n }} F_{[1,530]}=50.0, p<0.0001\right)$ over the late summer growing season measurement period, as would be expected for the onset of autumn senescence (Figs. $7 a, 7 b)$. Snow regime also had a significant effect in both gradients $\left(\right.$ Snow $_{\text {exp }}: F_{[2,528]}=80.82, p<0.0001$; Snow $\left.{ }_{\text {nat }}: F_{[2,530]}=6.17, p=0.0022\right)$. In the natural gradient, the NDVI was the same in Low $_{\text {nat }}$ and Deep nat $_{\text {and }}$ and significantly lower in Medium nat $_{\text {t }}$ (Table 5, Fig. 7a). In the experimental gradient, Low ${ }_{\text {exp }}$ also had the highest NDVI in both

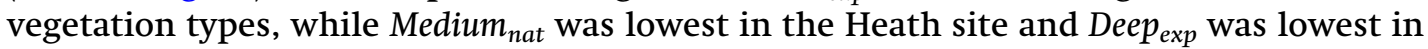
the Meadow site (Table 5, Fig. 7b). The NDVI was initially higher and declined at a faster rate over time in the Heath site than in the Meadow site (Figs. 7a, 7b; Vegetation $_{\text {exp }}$ : not significant; Vegetation ${ }_{\text {nat }}: F_{[1,4]}=11.5, p=0.0275$ ).

The OTC treatment significantly decreased the NDVI value by 0.03 compared with the control in all snow regimes (Fig. $7 c$; Treatment: $F_{[1,166]}=24.584, p<0.0001$ ).

\section{Discussion}

Timing of senescence in experimental and natural snowmelt gradients

Our results show that experimental and natural gradient studies lead to similar conclusions regarding the response of plants to changes in snow conditions in three out of the four studied species (S. polaris, Bistorta vivipara, and O. digyna). In our study, the snowmelt timing in the experimental gradient was the same as the corresponding snow regime in the natural gradient, which could imply that the timing of autumn senescence in Bistorta vivipara is linked to snowmelt timing. This species senesces the latest in Medium exp $_{\text {and }}$ and Medium $_{\text {nat }}$ snow regime plots (Fig. $3 b$ ), indicating the presence of the most optimal conditions for a longer growing season. The senescence timing in S. polaris and 0 . digyna was not affected by snow regime after 10 years of experimentally modified snowmelt timing. This response persisted along the long-term, natural gradient, implying that the mechanism for responding to changes in snowmelt timing is the same during short-term and long-term climate variations. In $S$. polaris, the DAS decreased with later snowmelt. According to Gehrmann et al. (2017), phenophases that occur synchronously but require fewer DAS along a snow gradient may be under photoperiodic control or other 
environmental regulation such as temperature changes. In our study location, day length was $24 \mathrm{~h}$ during the entirety of the study period, so it is unlikely to control senescence onset in $S$. polaris. Changes in spectral composition have been suggested to affect autumn senescence of deciduous trees (Brelsford et al. 2019) but the effect on tundra shrubs is unknown. The compensation response of a decrease in DAS with later snowmelt could instead be due to faster development of plants in later melting areas, as temperatures are higher compared with earlier melting plots upon melt-out. Oberbauer et al. (2013) found that the timing of senescence in Arctic plants is advancing with higher spring and summer temperatures, suggesting that senescence timing could be controlled by growing season temperatures.

In D. octopetala, the results from the natural gradient, on the one hand, suggest that increased snow depth and delayed snowmelt timing will not change the timing of autumn senescence. Projected increases in winter precipitation would therefore lead to a shorter growing season, as this would delay the onset of growth while not extending the end of the growing season. The experimental gradient, on the other hand, suggests that medium snow depth in mesic sites delays senescence in D. octopetala, thereby compensating for the delayed start in spring to some extent. The NDVI measurements, however, which were made at the plot level, suggest that little snow cover (as in the Low $w_{n a t}$ and Low exp plots) delays the beginning of autumn senescence the most and that the rate of autumn browning is strongly dependent on vegetation type (Fig. 7). NDVI values are strongly dependent on both the type of vegetation and the amount of vegetation coverage, both of which are altered by the snow manipulation (Riedel et al. 2005; Cooper et al. 2019). While this could explain the divergence in results between different methods, it also highlights the need to employ a variety of methods to understand both species- and community-scale responses.

Although we saw similar responses in the timing of autumn senescence to experimental and natural snowmelt gradients, we were able to simultaneously address different aspects of plant responses to climate with this combination of approaches. Short-term (a few years to a few decades) experiments, such as this snow manipulation, show whether plant phenology is plastic. This plasticity enables plants to respond immediately to a changing climate before genetic changes can take place. Observations along natural gradients, on the other hand, show the long-term adaptation to climate change, which can include plasticity in the phenology or genetic differentiation of phenological timing. Such a combination approach remains rare even though it is critical to estimate the contributions of phenotypic plasticity and evolutionary adaptation (Shaver et al. 2000; Dunne et al. 2004).

\section{Species-specific differences in senescence timing along snow depth gradients}

We found species-specific differences in the response of the onset of senescence to the timing of spring snowmelt and the depth of winter snow. Semenchuk et al. (2016) measured senescence timing over several years in three of the four species (Bistorta vivipara, $D$. octopetala, S. polaris) investigated here in the same snow fence experiment and reported on the mid-point of senescence of the vegetation plots, rather than onset as we present here. They found that senescence was delayed by approximately 10 days in Deepexp compared with Low $w_{\text {exp }}$ in all of these species. This difference is greater than the delay (or lack of delay) in phenology in the species in the present study. However, the study by Semenchuk et al. (2016) only measured phenology once a week and therefore could not reliably detect shifts in phenology of only a few days. They also found that the shift in senescence timing along the snow gradient is not the same between different years. While some yearly variation in plant responses can be expected due to a certain degree of phenotypic plasticity, both our study and Semenchuk et al. (2016) showed a similar direction in the plant responses, i.e., no advance in senescence. Yearly variation and greater 
measurement intervals may explain the difference between our results and those from the literature and act as modifiers on the plant responses. Species-specific differences in the response of phenology to snow regimes are common in the literature (e.g., Wipf et al. 2009; Wipf and Rixen 2010; Cooper et al. 2011) and some studies suggest that growth form or temporal niche of a species determines their response to snowmelt timing or snow depth (Wipf 2010; Petraglia et al. 2014; Khorsand Rosa et al. 2015; Livensperger et al. 2016), but our study could not confirm this. It has been found that genetic adaptation could account for $20 \%-75 \%$ of changes in flowering time in response to climate change in Boechera stricta (Graham) Al-Shehbaz, with larger changes calculated for shorter generation times (Anderson et al. 2012). Short-lived, herbaceous species may be more strongly controlled by genetic adaptation than long-lived woody species. These effects of stronger genetic adaptation and shorter generation times could play a role in the stronger variation in senescence timing we see in the herbaceous species Bistorta vivipara compared with the woody species $S$. polaris. Senescence timing can also be affected by bud burst timing. Bud burst responds strongly to snowmelt timing, but many Arctic species retain the same duration for some phenophases, so that shifts in senescence timing can be a lag effect of shifted bud burst (Semenchuk et al. 2016). In our study, bud burst data were not available.

In our study, snow regime and temperature increase did not alter senescence timing in o. digyna, so the onset of senescence is likely controlled by another factor in this species. It was recently shown that the timing of leaf-out and senescence of 0 . digyna follow a clear latitudinal trend, suggesting that day length and (or) spectral composition could be an important phenological control for this species (Bjorkman et al. 2017). This would support our result that senescence timing was the same along the snow gradients, as all plants experienced the same photoperiod.

Lower soil moisture has previously been found to be correlated with earlier onset of senescence (Livensperger et al. 2019), but because it is confounded by snowmelt timing its effect is difficult to separate from snowmelt. In our study, we did not find significant differences in the mean soil moisture for the period 19 July to 6 August between vegetation types (Fig. 2). This is likely because the autumn in 2016 had relatively little precipitation, so even the poorer draining Meadow site did not accumulate as much moisture. Higher soil moisture has previously been measured in the Meadow compared with the Heath site especially shortly after snowmelt but the difference decreased in July (Cooper et al. 2011, 2019). Higher snow depth commonly led to higher soil moisture in this study site, although this difference is more pronounced shortly after snowmelt and not always significant when considering the whole-season mean of soil moisture (Cooper et al. 2019; Mörsdorf et al. 2019). While this study was not established to specifically test gradients in soil moisture, we additionally examined our data for a significant correlation between the mean soil moisture of the study period and the DOY (Appendix B). We found that DOY in S. polaris was significantly affected by soil moisture with opposing effects in the natural and the experimental gradient (Fig. B1, Table B1).

Increased nitrogen was measured in the soil and leaves of S. polaris in Deep $_{\text {exp }}$ plots in the snow experiment in previous studies (Semenchuk et al. 2015; Mörsdorf et al. 2019). In warmed winter soil under Deep $p_{\text {exp }}$ snow, vegetation type affects the availability of the increase in nutrients (Semenchuk et al. 2015), but it is currently not clear how nutrient availability affects senescence. Senescence is strongly linked to nutrient cycling because nutrient resorption takes place during that time, so it may indirectly be affected by soil moisture. Therefore, we may not have seen strong effects of vegetation type on senescence timing in this study due to the similar autumn soil moisture.

Overall, data on senescence timing in Arctic plants are still scarce and studies use different stages in the senescence process to define senescence onset, such as $1 \%, 50 \%$, or $100 \%$ 
leaf colouration (Abbandonato 2014). Furthermore, the progress of senescence from the onset (i.e., 1\% colouration) to the end (i.e., 100\% colouration) can take as long as 6 weeks (Abbandonato 2014; Semenchuk et al. 2016) and is therefore not directly comparable with measurements of a single senescence stage. These discrepancies make it difficult to directly compare study results and implies that a common measure of senescence timing is needed (Gallinat et al. 2015).

\section{Passive autumn warming}

In our study, D. octopetala was the only species for which the onset of senescence was significantly affected by the presence of the OTCs. A delay of 4 days in the leaf colouration of D. octopetala exposed to the same method of passive warming was also found by Walker et al. (1999). They suggest that the extension of the active period is possible because D. octopetala is a "wintergreen" plant, meaning it retains its leaves throughout the winter and greens up rapidly in spring during a leaf lifespan of approximately 2 years. They also found a higher C:N ratio in D. octopetala leaves from warmed plots in the autumn, which could represent a greater resorption efficiency from leaves due to internal $\mathrm{N}$ cycling. This is in contrast to the other species in our study, which senesced at the same time regardless of temperature conditions. In a meta-analysis of the International Tundra Experiment (ITEX), there was generally no treatment effect after 4 years of OTC treatment on the timing of senescence in various species in up to six different Arctic and alpine sites (Arft et al. 1999). A more recent meta-analysis including studies with up to 20 years of OTC treatment found a mean delay in senescence across 61 species (Collins et al. 2021), which could indicate that there is a lag of several years in the response of autumn senescence to warming. A recent review of ITEX found that the timing of senescence is overall not sensitive to temperature increases across time or space when considering multiple species across the Arctic (Prevéy et al. 2017). However, most data in these syntheses is from the subarctic and Low Arctic as senescence data from the High Arctic is rare. Due to the different light conditions in the High Arctic, we therefore do not know whether we can extrapolate along this latitudinal gradient. While these studies have employed OTCs throughout the whole growing season, our study shows that a selective passive warming of only the end of the growing season can already lead to the extension of senescence onset, at least for some species.

Shifts in senescence due to warming may be small and undetectable if summarised across several species, but our results show that substantial changes can be seen in individual species. The growing season length for D. octopetala in this location is only about 5.5 weeks (Cooper et al. 2011), so even a small lengthening of the growing season by 4 days, which we found here, is equivalent to a $10 \%$ increase of time available for growth and other essential processes. It has been proposed that as little as a 1-day increase in the length of the growing season increases the annual gross primary productivity by $0.6 \%$ (Piao et al. 2007). However, autumn warming increases respiration more than photosynthesis in northern ecosystems (Piao et al. 2008), so a delay in senescence caused by warming could severely impact net ecosystem exchange of carbon, potentially resulting in increased carbon gain. This is especially true in heath communities, where evergreen dwarf shrubs make a major contribution to net ecosystem exchange (Strimbeck et al. 2019). To fully evaluate the changes in carbon dynamics caused by growing season shifts, the effect of climate changes during each season has to be evaluated separately. Furthermore, the progression of senescence needs to be considered from the onset (first colouration) to the end (leaf fall), as each phase during senescence can be differentially influenced by environmental factors and can vary greatly across habitats, years, and phylogeny (Abbandonato 2014; Panchen et al. 2015). 


\section{Conclusions}

Climate change will not affect all seasons equally and changes in one season can have a legacy effect on plant responses in another season. We have shown here that spring snowmelt and passive autumn warming both affect the timing of autumn senescence. The timing of autumn senescence is critical for plant ecology and ecosystem cycling because the length of the photosynthetic activity in plants determines plant productivity, nutrient and water cycling, and carbon uptake and release. To understand how these processes will be affected by climate change, we should study the plant responses using a variety of methods and scales. Our results showed that combining different study methods, such as experiments and natural gradients, and different scales, such as the plant level observations and plot level NDVI measurements, can provide complementary insights into the short- and long-term plant responses. Applying multiple approaches in the same study helps to overcome the limitations inherent in individual approaches, to generate more robust scientific conclusions. In the future, we need to aim to combine different methods at overlapping temporal and spatial scales to develop a better understanding of how plants will be affected by climate change.

\section{Acknowledgements}

We thank Daniel Metcalfe (Umeå University) for providing helpful comments on the manuscript. This study was funded by the Arctic Field Grant, The Research Council of Norway (grant No. ES559874), and the Doctoral Programme in Plant Science scholarship, University of Helsinki, to FG.

\section{References}

Abbandonato, H. 2014. Autumn senescence response to a changing climate: effects of snow-depth on High Arctic plants. M.Sc. thesis, Dep. Arct. Mar. Biol. Univ. Tromsø, Tromsø.

Anderson, J.T., Inouye, D.W., McKinney, A.M., Colautti, R.I., and Mitchell-Olds, T. 2012. Phenotypic plasticity and adaptive evolution contribute to advancing flowering phenology in response to climate change. Proc. R. Soc. B Biol. Sci. 279(1743): 3843-3852. doi: 10.1098/rspb.2012.1051.

Arft, A.M., Walker, M.D., Gurevitch, J., Alatalo, J.M., Bret-Harte, M.S., Dale, M., et al. 1999. Response patterns of tundra plants to experimental warming: a meta-analysis of the International Tundra Experiment. Ecol. Monogr. 69(4): 491-511.

Barnes, B. V., Zak, D.R., Denton, S.R., and Spurr, S.H. 1998. Forest Ecology. Wiley, New York, USA.

Bjorkman, A.D., Vellend, M., Frei, E.R., and Henry, G.H.R. 2017. Climate adaptation is not enough: warming does not facilitate success of southern tundra plant populations in the high Arctic. Glob. Chang. Biol. 23(4): 1540-1551. doi: 10.1111/gcb.13417. PMID: 27391174.

Blume-Werry, G., Kreyling, J., Laudon, H., Milbau, A., and Gilliam, F. 2016a. Short-term climate change manipulation effects do not scale up to long-term legacies: effects of an absent snow cover on boreal forest plants. J. Ecol. 104(6): 1638-1648. doi: 10.1111/1365-2745.12636.

Blume-Werry, G., Wilson, S.D., Kreyling, J., and Milbau, A. 2016b. The hidden season: Growing season is $50 \%$ longer below than above ground along an arctic elevation gradient. New Phytol. 209(3): 978-986. doi: 10.1111/nph.13655.

De Boeck, H.J., De Groote, T., and Nijs, I. 2012. Leaf temperatures in glasshouses and open-top chambers. New Phytol. 194(4): 1155-1164. doi: 10.1111/j.1469-8137.2012.04117.x. PMID: 22448800.

Bokhorst, S., Huiskes, A., Aerts, R., Convey, P., Cooper, E.J., Dalen, L., et al. 2013. Variable temperature effects of Open Top Chambers at polar and alpine sites explained by irradiance and snow depth. Glob. Chang. Biol. 19(1): 64-74. doi: 10.1111/gcb.12028. PMID: 23504721.

Brelsford, C.C., Nybakken, L., Kotilainen, T.K., Robson, T.M., and Polle, A. 2019. The influence of spectral composition on spring and autumn phenology in trees. Tree Physiol. 39(6): 925-950. doi: 10.1093/treephys/tpz026. PMID: 30901060.

Carbognani, M., Bernareggi, G., Perucco, F., Tomaselli, M., and Petraglia, A. 2016. Micro-climatic controls and warming effects on flowering time in alpine snowbeds. Oecologia 182(2): 573-585. doi: 10.1007/s00442-016-3669-3. PMID: 27299914.

Chylek, P., Folland, C.K., Lesins, G., Dubey, M.K., and Wang, M. 2009. Arctic air temperature change amplification and the Atlantic Multidecadal Oscillation. Geophys. Res. Lett. 36: L14801. doi: 10.1029/2009GL038777.

Collins, C.G., Elmendorf, S.C., Hollister, R.D., Henry, G.H.R., Clark, K., Bjorkman, A.D., et al. 2021. Experimental warming differentially affects vegetative and reproductive phenology of tundra plants. Nat. Commun. doi: 10.1038/s41467-021-23841-2. 
Cooper, E.J. 2014. Warmer shorter winters disrupt Arctic terrestrial ecosystems. Annu. Rev. Ecol. Evol. Syst. 45(1): 271-295. doi: 10.1146/annurev-ecolsys-120213-091620.

Cooper, E.J., Dullinger, S., and Semenchuk, P. 2011. Late snowmelt delays plant development and results in lower reproductive success in the High Arctic. Plant Sci. 180(1): 157-167. doi: 10.1016/j.plantsci.2010.09.005. PMID: 21421357.

Cooper, E.J., Little, C.J., Pilsbacher, A.K., and Mörsdorf, M.A. 2019. Disappearing green: Shrubs decline and bryophytes increase with nine years of increased snow accumulation in the High Arctic. J. Veg. Sci. 30(5): 857-867. doi: 10.1111/jvs.12793.

Dunne, J.A., Saleska, S.R., Fischer, M.L., and Harte, J. 2004. Integrating Experimental and Gradient Methods in Ecological Climate Change Research. Ecology 85(4): 904-916. doi: 10.1890/03-8003.

Fukami, T., and Wardle, D.A. 2005. Long-term ecological dynamics: Reciprocal insights from natural and anthropogenic gradients. Proc. R. Soc. B Biol. Sci. 272(1577): 2105-2115. doi: 10.1098/rspb.2005.3277.

Gallinat, A.S., Primack, R.B., and Wagner, D.L. 2015. Autumn, the neglected season in climate change research. Trends Ecol. Evol. 30(3): 169-176. doi: 10.1016/j.tree.2015.01.004. PMID: 25662784.

Gehrmann, F., Hänninen, H., Liu, C., and Saarinen, T. 2017. Phenological responses to small-scale spatial variation in snowmelt timing reveal compensatory and conservative strategies in subarctic-alpine plants. Plant Ecol. Divers. 10(5-6): 453-468. doi: 10.1080/17550874.2018.1428693.

Gehrmann, F., Lehtimäki, I.M., Hänninen, H., and Saarinen, T. 2020. Sub-Arctic alpine Vaccinium vitis-idaea exhibits resistance to strong variation in snowmelt timing and frost exposure, suggesting high resilience under climatic change. Polar Biol. 43(10): 1453-1467. doi: 10.1007/s00300-020-02721-3.

Henry, G.H.R., and Molau, U. 1997. Tundra plants and climate change: the International Tundra Experiment (ITEX). Glob. Chang. Biol. 3: 1-9. doi: 10.1111/j.1365-2486.1997.gcb132.x.

Hollister, R.D., Webber, P.J., Nelson, F.E., and Tweedie, C.E. 2006. Soil thaw and temperature response to air warming varies by plant community: Results from an open-top chamber experiment in northern Alaska. Arctic, Antarct. Alp. Res. 38(2): 206-215. doi: 10.1657/1523-0430(2006)38[206:STATRT]2.0.CO;2.

Humlum, O., Instanes, A., Sollid, J.L., Humlum, O., Instanes, A., and Sollid, J.L. 2003. Permafrost in Svalbard: a review of research history, climatic background and engineering challenges. Polar Res. 22(2): 191-215. doi: 10.1111/j.1751-8369.2003.tb00107.x.

IPCC 2013. Climate change 2013: the physical science basis. contribution of working group i to the fifth assessment report of the intergovernmental panel on climate change. Edited by T.F. Stocker, D. Qin, G.-K. Plattner, M. Tignor, S.K. Allen, J. Boschung, et al. Cambridge University Press, Cambridge.

Keenan, T.F., and Richardson, A.D. 2015. The timing of autumn senescence is affected by the timing of spring phenology: implications for predictive models. Glob. Chang. Biol. 21(7): 2634-2641. doi: 10.1111/gcb.12890. PMID: 25662890.

Khorsand Rosa, R., Oberbauer, S.F., Starr, G., Parker La Puma, I., Pop, E., Ahlquist, L., and Baldwin, T. 2015. Plant phenological responses to a long-term experimental extension of growing season and soil warming in the tussock tundra of Alaska. Glob. Chang. Biol. 21(12): 4520-4532. doi: 10.1111/gcb.13040. PMID: 26183112.

Kudo, G. 1991. Effects of snow-free period on the phenology of alpine plants inhabiting snow patches. Arct. Alp. Res. 23(4): 436-443. doi: 10.2307/1551685.

Kudo, G., and Suzuki, S. 1999. Flowering phenology of alpine plant communities along a gradient of snowment timing. Polar Biosci. 12: 100-113.

Lenth, R., Singmann, H., Love, J., Buerkner, P., and Herve, M. 2019. emmeans: Estimated Marginal Means, aka LeastSquares Means. R package version 1.3.6. Available from https://cran.r-project.org/package=emmeans.

Leuzinger, S., Luo, Y., Beier, C., Dieleman, W., Vicca, S., and Körner, C. 2011. Do global change experiments overestimate impacts on terrestrial ecosystems? Trends Ecol. Evol. 26(5): 236-241. doi: 10.1016/j.tree.2011.02.011. PMID: 21444122.

Livensperger, C., Steltzer, H., Darrouzet-Nardi, A., Sullivan, P.F., Wallenstein, M., and Weintraub, M.N. 2019. Experimentally warmer and drier conditions in an Arctic plant community reveal microclimatic controls on senescence. Ecosphere, 10(4). doi: 10.1002/ecs2.2677.

Livensperger, C., Steltzer, H., Darrouzet-Nardi, A., Sullivan, P.F., Wallenstein, M.D., and Weintraub, M.N. 2016. Earlier snowmelt and warming lead to earlier but not necessarily more plant growth. AoB Plants, 8: plw021. doi: 10.1093/aobpla/plw021. PMID: 27075181.

Marchand, F.L., Nijs, I., Heuer, M., Mertens, S., Kockelbergh, F., Marchand, F.L., et al. 2004. Climate warming postpones senescence in High Arctic tundra. Arct. Antarct. Alp. Res. 36(4): 390-394. doi: 10.1657/1523-0430(2004) 036[0390:CWPSIH]2.0.CO;2.

Marion, G.M., Henry, G.H.R., Freckman, D.W., Johnstone, J., Jones, G., Jones, M.H., et al. 1997. Open-top designs for manipulating field temperature in high-latitude ecosystems. Glob. Chang. Biol. 3(S1): 20-32. doi: 10.1111/j.13652486.1997.gcb136.x.

May, J.D., and Killingbeck, K.T. 1992. Effects of Preventing Nutrient Resorption on Plant Fitness and Foliar Nutrient Dynamics. Ecology, 73(5): 1868-1878. doi: 10.2307/1940038.

McBean, G., Alekseev, G., Chen, D., Førland, E., Fyfe, J., Groisman, P.Y., et al. 2005. Arctic climate: past and present. In Arctic Climate Impacts Assessment (ACIA). Edited by C. Symon, L. Arris, and B. Heal, eds. Cambridge University Press, Cambridge. pp. 21-60

Morgner, E., Elberling, B., Strebel, D., and Cooper, E.J. 2010. The importance of winter in annual ecosystem respiration in the High Arctic: effects of snow depth in two vegetation types. Polar Res. 29(1): 58-74. doi: 10.1111/j.17518369.2010.00151.x. 
Mörsdorf, M.A., Baggesen, N.S., Yoccoz, N.G., Michelsen, A., Elberling, B., Ambus, P.L., and Cooper, E.J. 2019. Deepened winter snow significantly influences the availability and forms of nitrogen taken up by plants in High Arctic tundra. Soil Biol. Biochem. 135: 222-234. doi: 10.1016/j.soilbio.2019.05.009.

Oberbauer, S.F., Elmendorf, S.C., Troxler, T.G., Hollister, R.D., Rocha, A.V., and Bret-Harte, M.S., et al. 2013. Phenological response of tundra plants to background climate variation tested using the International Tundra Experiment. Philos. Trans. R. Soc. Lond. B. Biol. Sci. 368(1624): 20120481. doi: 10.1098/rstb.2012.0481. PMID: 23836787.

Panchen, Z.A., Primack, R.B., Gallinat, A.S., Nordt, B., Stevens, A., Du, Y., and Fahey, R. 2015. Substantial variation in leaf senescence times among 1360 temperate woody plant species: implications for phenology and ecosystem processes. Ann. Bot. 116: 865-873. doi: 10.1093/aob/mcv015. PMID: 25808654.

Petraglia, A., Tomaselli, M., Petit Bon, M., Delnevo, N., Chiari, G., and Carbognani, M. 2014. Responses of flowering phenology of snowbed plants to an experimentally imposed extreme advanced snowmelt. Plant Ecol. 215(7): 759-768. doi: 10.1007/s11258-014-0368-1.

Piao, S., Ciais, P., Friedlingstein, P., Peylin, P., Reichstein, M., Luyssaert, S., et al. 2008. Net carbon dioxide losses of northern ecosystems in response to autumn warming. Nat. Lett. 451: 49-52. doi: 10.1038/nature06444.

Piao, S., Friedlingstein, P., Ciais, P., Viovy, N., and Demarty, J. 2007. Growing season extension and its impact on terrestrial carbon cycle in the Northern Hemisphere over the past 2 decades. Global Biogeochem. Cycles 21(3). doi: $10.1029 / 2006$ GB002888.

Pinheiro, J., Bates, D., DebRoy, S., Sarkar, D., and R Core Team 2020. nlme: Linear and Nonlinear Mixed Effects Models. R package version 3.1-147.

Prevéy, J., Vellend, M., Rüger, N., Hollister, R.D., Bjorkman, A.D., Myers-Smith, I.H., et al. 2017. Greater temperature sensitivity of plant phenology at colder sites: implications for convergence across northern latitudes. Glob. Chang. Biol. 23: 2660-2671. doi: 10.1111/gcb.13619. PMID: 28079308.

R Core Team. 2020. R: A language and environment for statistical computing. R Foundation for Statistical Computing, Vienna, Austria.

Räisänen, J. 2008. Warmer climate: Less or more snow? Clim. Dyn. 30(2-3): 307-319. doi: 10.1007/s00382-007-0289-y.

Riedel, S.M., Epstein, H.E., and Walker, D.A. 2005. Biotic controls over spectral reflectance of arctic tundra vegetation. Int. J. Remote Sens. 26(11): 2391-2405. doi: 10.1080/01431160512331337754.

Sedlacek, J., Wheeler, J.A., Cortés, A.J., and Bossdorf, O. 2015. The response of the alpine dwarf shrub Salix herbacea to altered snowmelt timing: lessons from a multi-site transplant experiment. PLoS ONE, 1-19. doi: 10.5061/ dryad.12c56.

Semenchuk, P.R., Elberling, B., Amtorp, C., Winkler, J., Rumpf, S., Michelsen, A., and Cooper, E.J. 2015. Deeper snow alters soil nutrient availability and leaf nutrient status in High Arctic tundra. Biogeochemistry 124: 81-94. doi: 10.1007/s10533-015-0082-7.

Semenchuk, P.R., Gillespie, M.A.K., Rumpf, S.B., Baggesen, N., Eberling, B., and Cooper, E.J. 2016. High Arctic plant phenology is determined by snowmelt patterns but duration of phenological periods is fixed: an example of periodicity. Environ. Res. Lett. 11: 125006. doi: 10.1088/1748-9326/11/12/125006.

Serreze, M.C., Barrett, A.P., Stroeve, J.C., Kindig, D.N., and Holland, M.M. 2009. The emergence of surface-based Arctic amplification. Cryosph. 3: 11-19. doi: 10.5194/tc-3-11-2009.

Shaver, G.R., Canadell, J., Chapin, F.S., III, Gurevitch, J., Harte, J., Henry, G., et al. 2000. Global warming and terrestrial ecosystems: A conceptual framework for analysis. Bioscience 50(10): 871-882. doi: 10.1641/0006-3568(2000) 050[0871:GWATEA]2.0.CO;2.

Strimbeck, G.R., Graae, B.J., Lang, S., and Sørensen, M.V. 2019. Functional group contributions to carbon fluxes in arctic-alpine ecosystems. Arctic, Antarct. Alp. Res. 51(1): 58-68. doi: 10.1080/15230430.2019.1578163.

Walker, M.D., Walker, D.A., Welker, J.M., Arft, A.M., Bardsley, T., Brooks, P.D., et al. 1999. Long-term experimental manipulation of winter snow regime and summer temperature in arctic and alpine tundra. Hydrol. Process. 13: 2315-2330. doi: 10.1002/(SICI)1099-1085(199910)13:14/15<2315::AID-HYP888>3.0.CO;2-A.

Wheeler, H.C., Høye, T.T., Schmidt, N.M., Svenning, J.-C., and Forchhammer, M.C. 2015. Phenological mismatch with abiotic conditions - implications for flowering in Arctic plants. Ecology 96(3): 775-787. doi: 10.1890/140338.1. PMID: 26236873.

Wipf, S. 2010. Phenology, growth, and fecundity of eight subarctic tundra species in response to snowmelt manipulations. Plant Ecol. 207(1): 53-66. doi: 10.1007/s11258-009-9653-9.

Wipf, S., and Rixen, C. 2010. A review of snow manipulation experiments in Arctic and alpine tundra ecosystems. Polar Res. 29(1): 95-109. doi: 10.1111/j.1751-8369.2010.00153.x.

Wipf, S., Stoeckli, V., and Bebi, P. 2009. Winter climate change in alpine tundra: Plant responses to changes in snow depth and snowmelt timing. Clim. Change 94(1-2): 105-121. doi: 10.1007/s10584-009-9546-x.

Wolkovich, E.M., Cook, B.I., Allen, J.M., Crimmins, T.M., Betancourt, J.L., Travers, S.E., et al. 2012. Warming experiments underpredict plant phenological responses to climate change. Nature 485(7399): 494-497. doi: 10.1038/ nature11014. PMID: 22622576. 


\section{Appendix A}

Fig. A1. (a) Air temperature and (b) soil temperature measured during the period 31 July to 6 August in control plots (solid line) and open top chambers (dashed lines) along a natural snow depth gradient with Low, Medium, or Deep snow regimes, as well as the temperature measured at the nearest weather station (Airport) at Svalbard Airport.

(a)

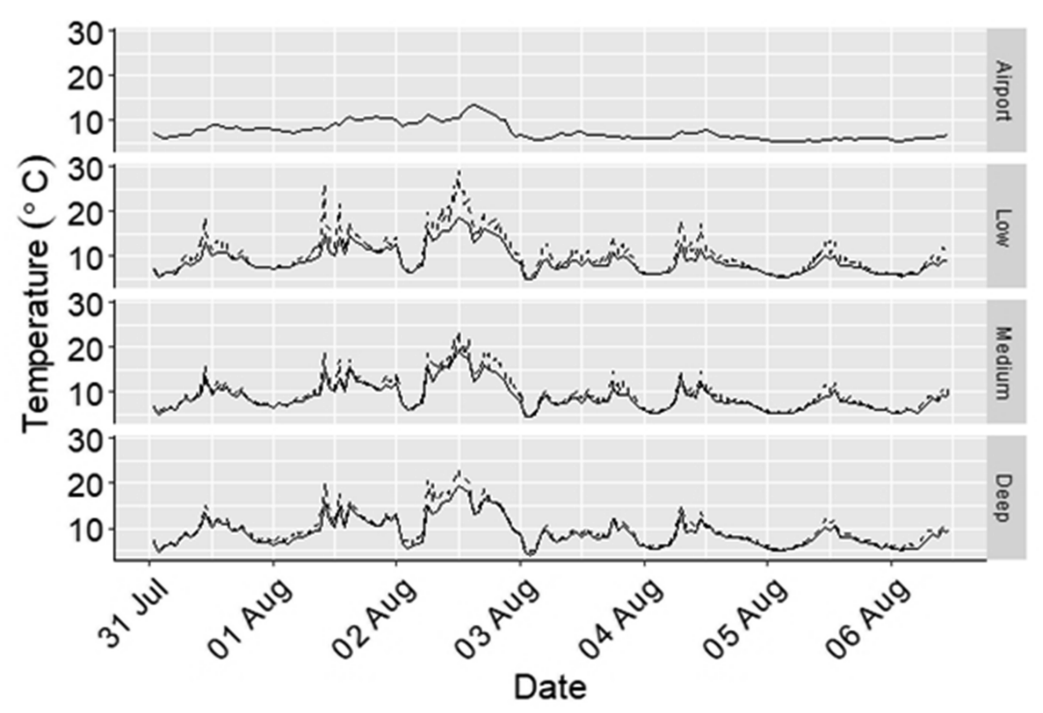

(b)

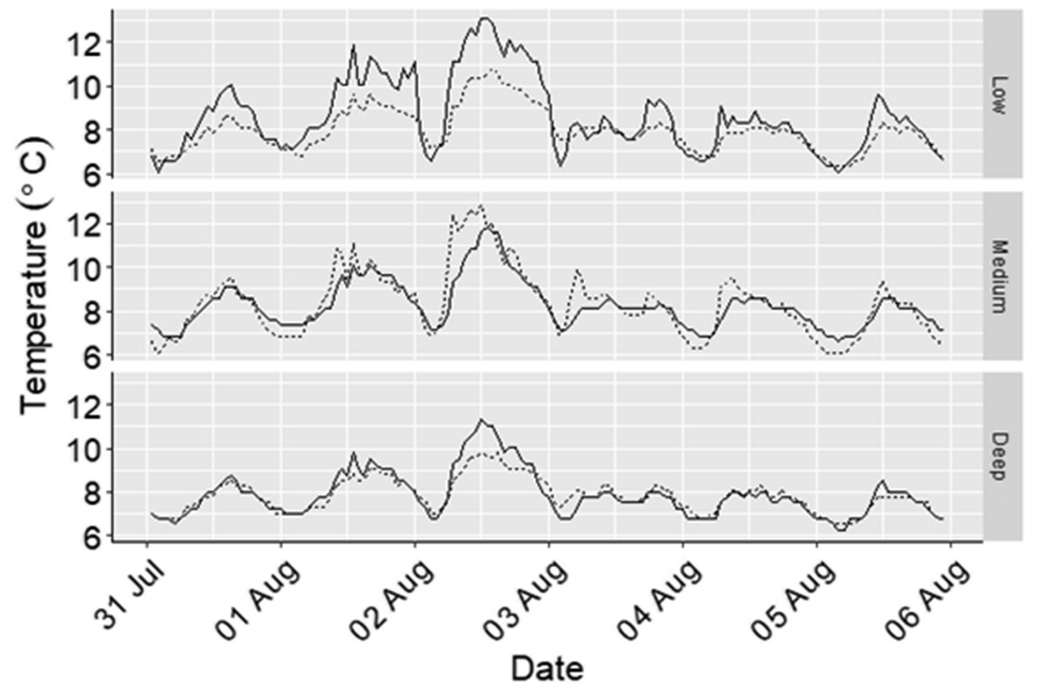

Published by Canadian Science Publishing 


\section{Appendix B}

Method

We additionally examined our data for the effect of soil moisture on the DOY of senescence. This was done by first calculating the mean soil moisture (volumetric water content, \%) of the whole study period (19 July to 6 August 2016) for each plot ("SM_Season") as a representation of the relative wetness of each plot. Then, DOY was modelled as a function of Snow, Vegetation, and SM_Season in a linear mixed-effects model with Site and Plot as random effects. The model was fitted for each species and each gradient type (natural or experimental) separately.

Fig. B1. The mean day of year (DOY) of the onset of senescence in S. polaris in (a) an experimental and (b) a natural snowmelt gradient in two different Vegetation types (Heath, Meadow) and plots with differing mean autumn soil moisture (SM_Season). Only significant relationships between DOY and explanatory variables are displayed. Mean autumn soil moisture was calculated as the mean soil moisture during the study period for each individual plot. VWC, volumetric water content.

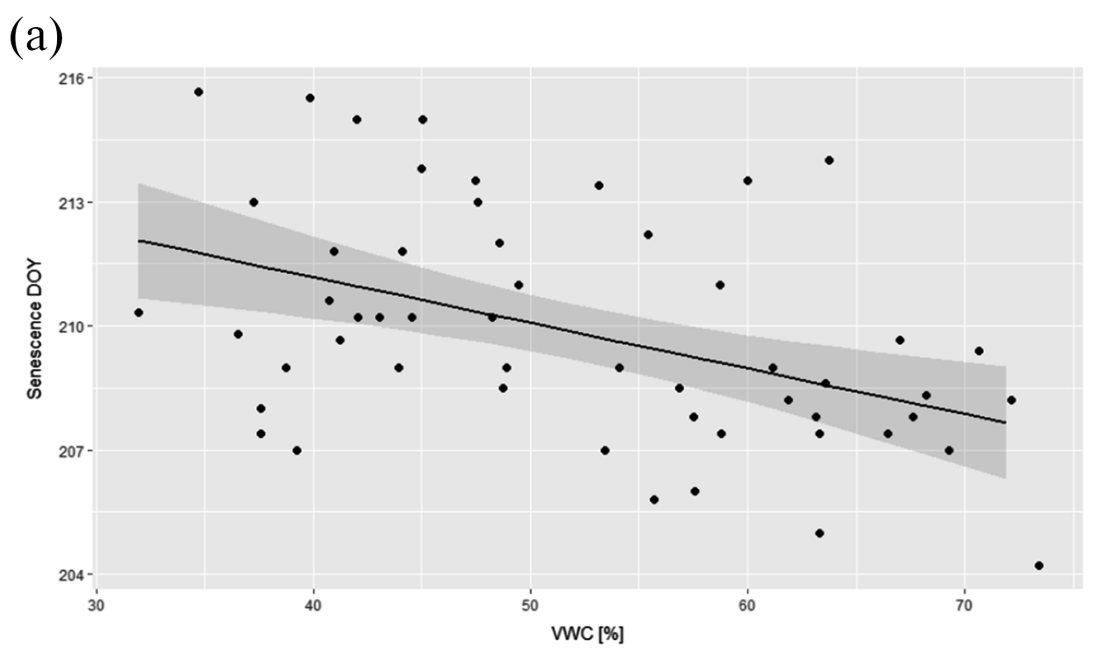

(b)

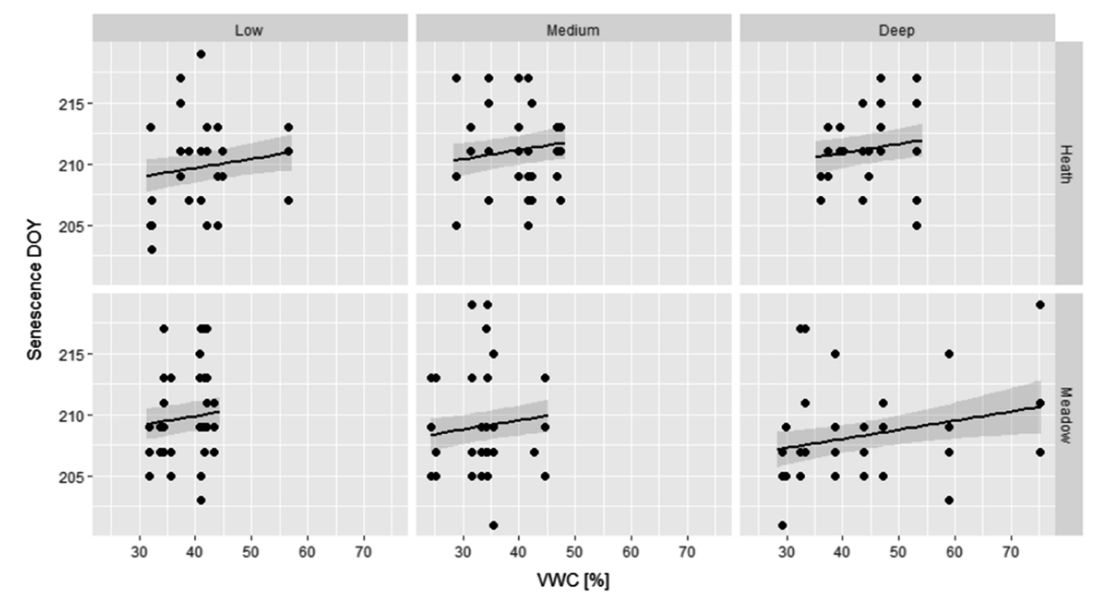

Published by Canadian Science Publishing 
Table B1. Analysis of variances results of linear mixed-effects models testing the effect of mean soil moisture during the study period (SM_Season), snow regime (Snow), and vegetation type (Vegetation) on the day of year of senescence in $S$. polaris in a natural and an experimental snowmelt gradient.

\begin{tabular}{lllll}
\hline & SM_Season & Snow & Vegetation & Snow $\times$ Vegetation \\
\hline Natural gradient & $F_{[1,43]}=6.8, p=0.012$ & n.s. & $F_{[1,4]}=8.1, p=0.047$ & $F_{[2,43]}=3.4, p=0.0437$ \\
Experimental gradient & $F_{[1,46]}=13.1, p<0.001$ & n.s. & n.s. & n.s. \\
\hline
\end{tabular}

Note: n.s., not significant.

\section{Results}

The effect of mean soil moisture on the DOY was only significant in S. polaris. In the experimental gradient, higher soil moisture during the study period was correlated with an earlier DOY (Fig. B1, Table B1). In the natural gradient, the correlation was the opposite (Fig. B1, Table B1). Additionally, individuals in Meadow senesced overall 1.4 days earlier than in Heath and 1.9 days earlier in Meadow-Medium than in Meadow-Low. 